OPEN ACCESS

Edited by:

Cristina Maccalli,

Sidra Medicine, Qatar

Reviewed by:

Soldano Ferrone,

Massachusetts General Hospital and

Harvard Medical School,

United States

Pier Paolo Claudio,

University of Mississippi, United States

*Correspondence:

Ruggero De Maria

ruggero.demaria@unicatt.it

†These authors share first authorship

Specialty section:

This article was submitted to

Cancer Immunity and Immunotherapy,

a section of the journal

Frontiers in Immunology

Received: 15 April 2020

Accepted: 10 August 2020

Published: 21 October 2020

Citation:

Sistigu A, Musella M, Galassi C, Vitale I and De Maria R (2020) Tuning

Cancer Fate: Tumor

Microenvironment's Role in Cancer

Stem Cell Quiescence and

Reawakening.

Front. Immunol. 11:2166.

doi: 10.3389/fimmu.2020.02166

\section{Tuning Cancer Fate: Tumor Microenvironment's Role in Cancer Stem Cell Quiescence and Reawakening}

\author{
Antonella Sistigu ${ }^{1,2+}$, Martina Musella ${ }^{1+}$, Claudia Galassi ${ }^{1}$, Ilio Vitale ${ }^{3,4}$ and \\ Ruggero De Maria ${ }^{1,5 *}$
}

${ }^{1}$ Istituto di Patologia Generale, Università Cattolica del Sacro Cuore, Rome, Italy, ${ }^{2}$ Tumor Immunology and Immunotherapy Unit, IRCCS Regina Elena National Cancer Institute, Rome, Italy, ${ }^{3}$ IIGM - Italian Institute for Genomic Medicine, c/o IRCSS Candiolo (TO), Candiolo, Italy, ${ }^{4}$ Candiolo Cancer Institute, FPO - IRCCS, Candiolo, Italy, ${ }^{5}$ Fondazione Policlinico Universitario "A. Gemelli" - IRCCS, Rome, Italy

Cancer cell dormancy is a common feature of human tumors and represents a major clinical barrier to the long-term efficacy of anticancer therapies. Dormant cancer cells, either in primary tumors or disseminated in secondary organs, may reawaken and relapse into a more aggressive disease. The mechanisms underpinning dormancy entry and exit strongly resemble those governing cancer cell stemness and include intrinsic and contextual cues. Cellular and molecular components of the tumor microenvironment persistently interact with cancer cells. This dialog is highly dynamic, as it evolves over time and space, strongly cooperates with intrinsic cell nets, and governs cancer cell features (like quiescence and stemness) and fate (survival and outgrowth). Therefore, there is a need for deeper insight into the biology of dormant cancer (stem) cells and the mechanisms regulating the equilibrium quiescence-versus-proliferation are vital in our pursuit of new therapeutic opportunities to prevent cancer from recurring. Here, we review and discuss microenvironmental regulations of cancer dormancy and its parallels with cancer stemness, and offer insights into the therapeutic strategies adopted to prevent a lethal recurrence, by either eradicating resident dormant cancer (stem) cells or maintaining them in a dormant state.

Keywords: tumor microenvironment, cancer stem cells (CSC), disseminated cancer cells (DCC), reawakening, dormancy, immunoediting of cancer, immune escape, tumor evolution

\section{INTRODUCTION}

Despite the many noteworthy improvements in early diagnosis and treatment of primary tumors in recent years, in many cases, cancer patients develop distant metastases that, almost invariably, portend a poor prognosis. The current view is that metastatic relapse is caused by the reawakening of disseminated cancer cells (DCCs) from a dormant and asymptomatic state, after a time-lag lasting from a few months to several years.

Cancer dormancy is broadly defined as a stalled phase of cancer progression during which single cancer cells or microscopic tumor bulks remain clinically undetectable, yet retain the ability to progress into overt disease (1). Pristine mentions of cancer dormancy date back to the 1950s, when clinicians hypothesized that dormancy could explain cases of relapse observed several years 


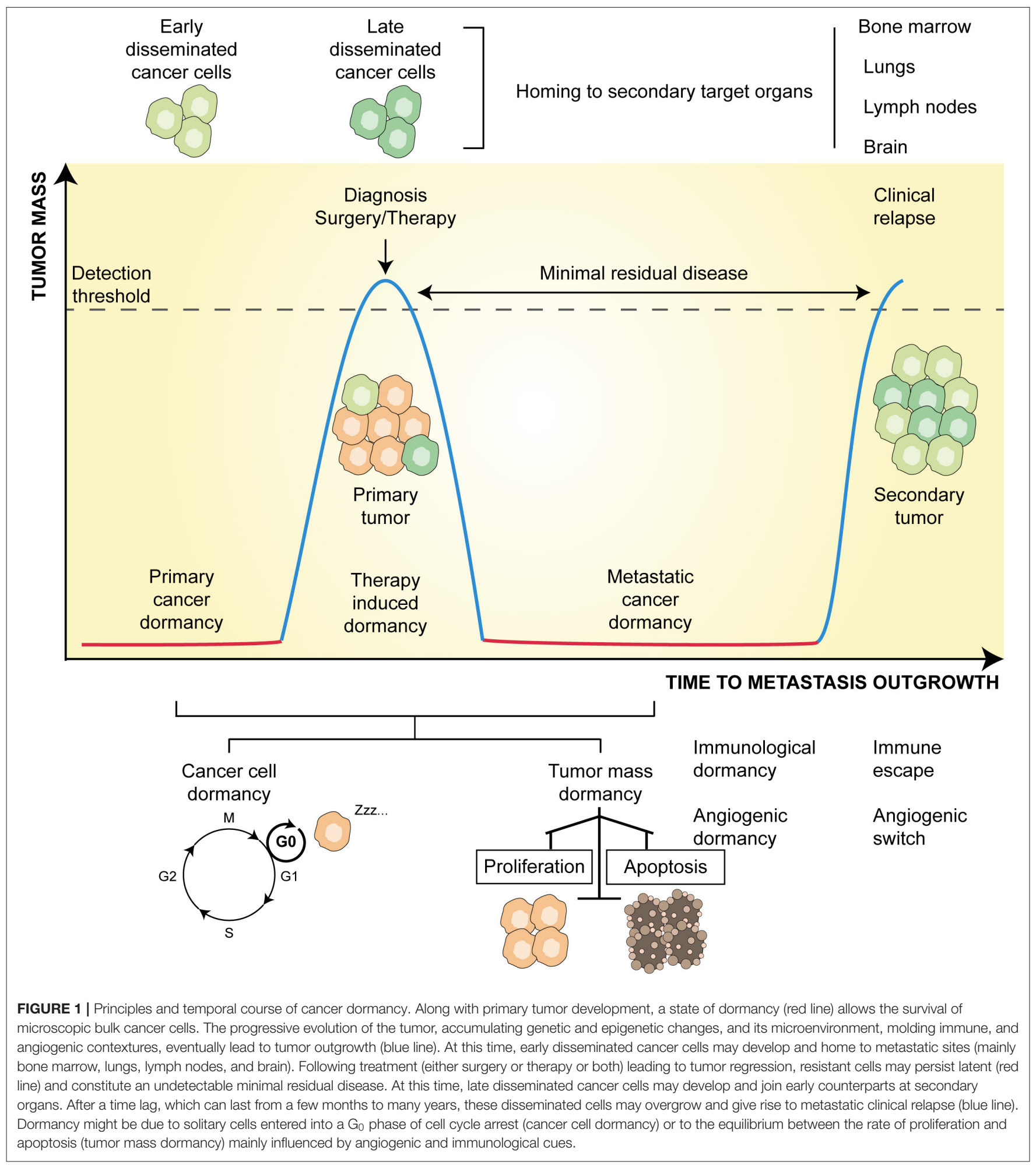

after post-surgical and post-therapy remission (2). Nowadays, it is well-proven that dormancy is an adaptive and protective mechanism that malignant cells adopt to survive stress conditions of the tumor microenvironment (TME) (3). Moreover, cancer dormancy is considered a crucial part of the natural history of cancer evolution, irrespective of whether it occurs during primary tumor development (primary dormancy) or metastatic colonization (metastatic dormancy) (4) (Figure 1). In this setting, if the TME is growth permissive, cancer cells proliferate and give rise to overt diseases. If instead, the TME is 
not-permissive, cancer cells either are eradicated via the activation of regulated cell death or an irreversible proliferative arrest known as cellular senescence or survive by entering reversible dormancy. Dormant cells could then contribute to disease evolution by increasing their fitness via enforcement of genetic and epigenetic editing (5), and/or by promoting the remodeling of the TME, which then becomes "fertile soil" for outgrowth (3).

Three additional layers of complexity are emerging in the field of cancer dormancy, all of which have therapeutic relevance. First, at the molecular level, both the entry to and exit from dormancy are finely regulated by the cooperative action of cellular and molecular components of the TME (3). Of note, these contextual cues trigger a multitude of dormancy inducing signaling, and almost all overlap with those that induce cancer stemness $(6,7)$. This is supported by the evidence that cancer stem cells (CSCs) - the subset of cancer cells endowed with self-renewal ability, therapy-resistance, and immune evasion $(8-10)$ - may switch between dormant and proliferative states $(6,7)$, resulting in an increased metastatic potential (11). Second, at the mechanistic level, tumor dormancy encompasses cellular dormancy (i.e., the condition in which solitary cancer cells temporarily arrest their cell cycle), and tumor mass dormancy, which refers to the condition in which clusters of indolent malignant cells enter a state of balanced proliferation/apoptosis rate (1). This balance, which prevents a tumor from increasing in size, seems to rely on (i) the absence of new vessel sprouting (so-called angiogenic dormancy) $(3,12)$, and (ii) immunosurveillance (so-called immunologic dormancy) $(3,13,14)$. Finally, even though cellular senescence is widely considered as an irreversible and persistent cell cycle arrest (15), instances of reversible senescence and a causal link of the latter to disease recurrence have also been reported $(7,16)$.

In this study, we first describe the process of metastasization and the experimental models developed to study cancer dormancy and then discuss the role of the TME factors in regulating cancer dormancy and reawakening at metastatic sites. In particular, we focus on the intimate cooperation between different TME signals as we cover the complex relationship between immune-mediated dormancy and dormancy-mediated immune escape. During these discussions, we highlight the striking parallels between cancer dormancy and cancer stemness and summarize the current use of and ensuing therapeutic opportunities to prevent the occurrence of life-threatening metastatic relapse.

\section{METASTASIS: MODELS, EVOLUTION AND DORMANCY}

It is estimated that metastatic relapse is responsible for as much as $90 \%$ of cancer-related deaths $(17,18)$. This is ascribed to the fact that progressing metastases rapidly become incurable, spread to additional sites, and compromise the function of vital organs (17). The clinical importance of cancer metastasis has been undeniable since the recognition of cancer as a disease, which has fostered massive experimental efforts to understand its origins and nature (19).

Taking stock of the increasingly large body of research to date, metastasis can be depicted as a sequential, multi-step process collectively conceptualized as the invasion-metastasis cascade (19-22). This sequence of events includes: (i) single cancer cell detachment from the primary tumor and infiltration of the surrounding tissues (invasion); (ii) stimulation of neo vessel sprouting (neoangiogenesis); (iii) entering of cancer cells into blood vessels (intravasation), where these cells acquire the status of circulating tumor cells (CTCs); (iv) survival of CTCs to the hematogenous environment; (v) the leakage of CTCs from the bloodstream (extravasation) followed by their homing to distant organs, where they acquire the status of DCCs; and ( $v i$ ) formation of micro metastatic bulks by DCCs and their adaptation to the new microenvironment (colonization) $(23,24)$. The metastatic cascade is full of rate-limiting steps, which explains why only a small percentage $(0.02 \%)$ of DCCs successfully take root and rise into overt metastases (25). Indeed, after homing to a distant site, DCCs face a new microenvironment almost always devoid of growth permissive factors, resulting in DCC demise/senescence or entry into dormancy $(1,23,26)$. As anticipated above, the acquisition of a dormant state is a strategy that enables cancer cells to perpetuate the disease while remaining under the radar for a protracted time, until both their fitness and the environmental conditions become permissive for growth (5). In this evolutionary process, the more DCC variants acquire genetic and epigenetic alterations, the higher is their probability of outgrowing in target organs.

Based on genetic comparative analysis studies, different evolutionary models have been proposed to explain the process of metastasization. In the linear progression model, metastases are late, even final events of primary tumor development (27) arising from the progressive accumulation of somatic alterations in cancer cells of the primary tumor $(28,29)$ that are under the selective pressure of heterotypic signals from the TME (30). Such a unidirectional timeline of events is initiated by the emergence of a cancer cell clone with metastatic capability followed by its dissemination to distinct organs. As a result, primary and metastatic sites are genetically related, although major differences can derive from the development of metastases from rare subclones $(27,31,32)$ or the acquisition of specific genetic/epigenetic variation at the primary and/or colonization site. On the contrary, the parallel progression model assumes that DCCs develop early during tumor onset, perhaps even before the formation of overt primary lesions (33-38). This model implies that primary and metastatic tumors evolve independently from each other, resulting in them having a completely different genetic makeup $(39,40)$. Hence, cancer cells may constantly disseminate during primary tumor progression and evolve, giving rise to different cell variants, outside of the primary lesion. Finally, the tumor self-seeding model postulates a bidirectional exchange of cancer cells between parallel primary and metastatic lesions, denying the hypothesis of independent tumor evolution at primary and colonization sites (41).

Irrespective of the precise metastatic model, DCCs surviving this process are generally incompetent at growing in colonization 
sites and enter dormancy. This is clinically relevant, as beyond enhancing cancer cell fitness and aggressiveness, metastatic dormancy also induces resistance to therapy (5). Indeed, as conventional anticancer therapies target rapidly proliferating cancer cells, quiescence appears as the most consistent defense strategy of tumors to resist therapy. In particular, therapy-related dormancy preserves the survival of such cell subpopulations, which are the precursors of tumor relapse constituting the socalled minimal residual disease (MRD) (42) (Figure 1).

Cancer dormancy stands out as more than simple quiescence and clinical undetectability, instead, it is a multifaceted and plastic phenomenon with a tremendous impact on therapy outcome and patient survival. This is the reason why dormancy represents a major clinical conundrum and a hot research topic in oncology. We need to gain further insights into the mechanisms governing cancer dormancy and reawakening, as this would open new avenues for preventing or treating metastatic disease. To accomplish this need, a number of experimental preclinical and computational models have been developed.

\section{MODELS OF CANCER DORMANCY: PRINCIPLES AND APPLICATIONS}

Over the past two decades, an intensive wave of investigation in the field of tumor dormancy has led to the development of various experimental models that investigate the molecular mechanisms and circuitries regulating dormancy as well as the intricate cross-talk between dormant cancer cells and host immune cells $(3,43)$. Experimental strategies conceived to study cancer dormancy encompass: (i) in vitro and ex vivo models; (ii) in vivo models; (iii) mathematical and computational models. Table 1 summarizes these current methods, which are also briefly described here.

\section{In vitro and ex vivo Models of Cancer Dormancy}

Despite constituting a highly simplified depiction of the TME, in vitro models of cancer dormancy provide major advantages including the unique possibility (i) to study, at a single cell resolution, the crosstalk between cancer cells and the other cellular and non-cellular components of the TME; and (ii) to functionally suppress or completely remove specific cell populations that are essential for animal survival and as such, difficult to be studied in in vivo models. The regulatory mechanisms identified through in vitro models, however, always need validation in more complex and realistic in vivo models.

Two-dimensional (2D) and three-dimensional (3D) cell cultures are the standard in vitro tools for investigating the mechanisms of cellular dormancy as well as the interactions with selected players of the microenvironment regulating major steps of dormancy such as cell cycle arrest, immunogenicity, differentiation, and therapeutic resistance. In the simplest 2D cell culture setting, cancer cells from either immortalized or primary cell lines are seeded on selected stromal components [e.g., fibronectin 1 (FN1), collagen I, collagen IV, among others] at clonogenic densities to favor cell interaction with the substratum and in the presence of microenvironmental
TABLE 1 | Models for studying cancer dormancy.

In vitro and ex vivo models

References

2D cultures:

Cancer cells are cultivated on extracellular matrix (ECM) component-coated plates.

Breast cancer + fibronectin + fibroblast growth factor-2

3D cultures:

Dormant cancer cells remain quiescent in $3 \mathrm{D}$ bioengineered models.

Biomaterial based model

Breast Cancer + Basement Membrane Matrix

Breast Cancer + Bone Marrow and Lung Niche Cells +

laminin-rich ECM

Breast Cancer + Bone Marrow Niche Cells + Collagen

biomatrix

Breast, Colon and Pancreatic Cancer + Stiff Col-Tgel

Bladder, Prostate Cancer + Prostate Niche Cells + Amikagel

Breast and Ovarian Cancer + Collagen gel

Melanoma + Fibrin gel

Brain Metastatic Breast Cancer + Hyaluronic Acid Hydrogel

Microfluidic based models/Organ-on-a-Chip

Breast Cancer + Hepatic Niche Cells + PEG hydrogel

LiverChip and Breast Cancer

Lung Cancer-on-a-Chip

Bioreactor based model

Breast Cancer + Bone Niche Cells

\section{In vivo models}

Mouse vaccination and tumor challenge

BCL1 mouse lymphoma model

DA1-3b of acute myeloid leukemia

\section{Experimental metastasis assays:}

Cancer cells are injected directly into the circulation (e.g., tail vein, left cardiac ventricle, iliac artery)

\section{Spontaneous metastasis assays:}

Cancer cells are injected orthotopically or subcutaneously.

Spontaneous tumor models:

Genetically engineered mouse models of oncogene

ablation/induction (e.g., Myc, Kras)

Transgenic mouse models (e.g., MMTV-PyMT,

MMTV-HER2, RET)

Resection mouse models

Mathematical and Computational models

Ordinary differential equations

soluble factors [e.g., epidermal growth factor (EGF) and basic fibroblast growth factor]. The effect of such extracellular matrix (ECM) factors on cancer cell dormancy, survival, and metastatic potential can then be evaluated by analyzing (as examples) cell clonogenic potential upon staining with crystal violet or cancer cell morphology, phenotype, cell cycle arrest, proteome and transcriptome employing standard methods of cellular and molecular biology (e.g., by microscopy, flow cytometry, western blot, qRT-PCR, and other techniques) $(44,45)$. In this setting, the $2 \mathrm{D}$ system can be easily perturbed by the addition of blocking antibodies, inhibitors, or peptides, partially mimicking the tumor microenvironmental conditions $(44,45)$. 
In this context, the recent development of microfluidic devices, bioreactors, and biomaterials, has driven researchers into a 3D cell culture-based multidisciplinary approach to detect, profile and even treat dormant cancer cells, spanning from fundamental biology to high-throughput screening (87-91). Indeed, cells cultured in a 3D model system more closely mimick the in vivo conditions and address most of the factors that can impact cancer dormancy, such as cell-to-cell and cell-to-ECM interactions, tissue architecture, proteomic and metabolomics profiles, and oxygen levels (92). 3D cell cultures can be generated by using either natural (Cultrex, laminin-rich ECM, collagen) (46-49) or synthetic biomaterials (collagen-based and fibrinbased hydrogels, amikagels, and hyaluronic acid hydrogels) (5054). Moreover, organ-on-chip 3D models provide a way to study cancer dormancy at growing steps of complexity from a cell, to tissue till organ levels, and offer the possibility to perform a real-time, high-resolution analysis taking into consideration the inter-tissue interfaces, the fluid flows, and mechanical strengths, which are all features known to affect tumor dormancy (5559). Similarly, bioreactors allow researchers to monitor and alter the chemical composition of the culture and thus to identify key chemical contributors to cancer dormancy and reawakening under controlled conditions (60).

Although highly informative and relatively simple, in vitro models are not devoid of caveats. The most significant hurdles of the in vitro systems are: (i) the need, in multicellular cultures, to optimize culturing protocols allowing the growth and survival of different cell types, (ii) the needs of organ-specific stromal cells, which are usually difficult to obtain, (iii) the difficulty of mimicking the dynamic evolution of the TME composition, and (iv) the challenge of replicating the complexity of the TME, and most notably the role of the immune system. Indeed, in vivo models represent a logical extension of in vitro findings providing a more comprehensive approach and enabling data validation.

\section{In vivo Models of Cancer Dormancy}

Five broad approaches are currently employed to investigate cancer dormancy in vivo: (i) vaccination assays, (ii) metastasis assays, either in induced or spontaneous settings, (iii) spontaneous tumor models, (iv) resection mouse models, and $(\mathrm{v})$ patient-derived xenograft (PDX) models.

In the vaccination assay, irradiated or otherwise killed malignant cells are inoculated into immunocompetent syngeneic mice. One-to-2 weeks later, the immunized animals are challenged with living cancer cells and monitored for the presence of persistent dormant cancer cells over long term follow up (from a few months to 1 year) $(61,62)$. As it stands, the gold-standard approach to evaluate the multi-organ dormancy of tagged cancer cells relies on metastasis assays. Metastases can be experimentally induced by injecting cancer cells into the tail vein (63-65) or the iliac artery (66). Otherwise, cancer cells can be injected subcutaneously or orthotopically and spontaneous metastatic potential can be monitored over time (67-69), or into genetically engineered mice that develop metastatic cancers $(33,70-73)$, or even humanized PDX models (76-78) can be used. All these assays allow in vivo live animal imaging and real-time monitoring of metastasis formation and growth, they provide countless insights into the mechanisms of metastatic dormancy and tumor persistence. Of note, as surgery could trigger metastatic relapse in patients with breast cancer (93), are socalled resection mouse models, which offer the possibility to link primary cancer surgery to the appearance of secondary disease at distant anatomical sites $(74,75)$ potentially helping unveil mechanisms of cancer cell dissemination and reawakening.

These multiplicities of in vivo models offer a holistic view of cancer dormancy and represent pre-clinical tools for clinical validation and intervention. However, in vivo studies also have some limitations. Indeed, cancer dormancy takes place over a long time frame and asynchronous heterogeneous dormant cancer cell populations are difficult to track. In this sense, the integration and merging of experimental data with mathematical models and computational simulations may provide insights and a better understanding of the regulatory circuits and the biological behaviors underlying dormancy, with invaluable benefits to translational research.

\section{Mathematical and Computational Models of Cancer Dormancy}

The last 15 years have witnessed significant advances in mathematical modeling and computational simulations of complex biological processes such as cancer evolution, response to therapy, and even dissemination and dormancy. The use of mathematics in cancer research, known as mathematical oncology, encompasses knowledge-based differential equation models that simulate and predict tumor dynamics and response to therapy. Mathematical oncology offers insights into the complexity and multiscale nature of cancer cell dormancy and dissemination, (i) by integrating experimental and clinical information (79-81), (ii) by mechanistically modeling tumor evolution and progression as a functional consequence of the complex interaction between cancer cells and the surrounding TME (82, 83), and (iii) by predicting and simulating the molecular pathways involved $(84,85)$. More recently, systems biology, a multidisciplinary approach that integrates cancer research and medicine, genetics and epigenetics, mathematics, physics, and bioinformatics has gained momentum in the study of cancer dormancy and reawakening, as provides a more comprehensive view of the dynamics of these complex processes (86).

The optimization, application, and integration of all these models will help our understanding of the complexity of cancer dormancy and the multiscale nature of cancer progression. Undoubtedly, this is a promising path forward to validate and translate experimental findings in clinical settings and overcome therapeutic resistance in cancer.

\section{CANCER DORMANCY AND CANCER STEMNESS: PARALLELS AND DIFFERENCES BETWEEN CULPRITS OF RELAPSE}

CSCs are the subpopulation of stem-like cells within the tumor mass that possess unique stem-like features such as longterm self-renewal capability, multi-lineage differentiation, and high resistance to stress and apoptosis $(9,94)$. Based on these 
properties, CSCs are considered the seeds of tumor initiation, progression, and metastatic relapse and mainly responsible for therapy failure and poor clinical outcomes $(9,94)$. Historically presumed to be a very small and quiescent subpopulation, it is now clear that CSCs may not always adhere to this model. Indeed, recent evidence shows that CSCs can be relatively abundant (at least in some tumors), able to alternate between dormant and proliferating states, characterized by a high degree of heterogeneity and plasticity over space (i.e., in distinct tumor regions) and time (i.e., at distinct tumor progression stages) (9). Moreover, subsets of CSCs were reported to differentiate into heterogeneous lineages of cancer cells including nonstem cells, and vice versa differentiated cells to undergo cell dedifferentiation and even adopt CSC features $(95,96)$. CSCs reside in niches, which are specialized regions within the TME, preserving CSC survival and metastatic potential and regulating dormancy-reawakening switches (97). However, to date, a univocal definition of CSCs is still missing, and a unified model of genetic and phenotypic biomarkers is very difficult to achieve. In light of this evidence, resting CSC functional markers on the most threatening properties of CSCs may likely be the key.

One such property is the ability of CSCs to enter and exit from dormancy that, in the majority of cancer types, is the sine qua non condition for surviving therapy and initiating metastases, which are the two lethal features of CSCs. Based on this striking analogy, some investigations have proposed that CSCs and dormant cells are two sides of the same coin $(6,98)$. Indeed, ever-increasing data show the parallels at the molecular level, between dormant DCCs and CSCs. To give some examples, the activation of the p38 mitogen-activated protein kinase 1 (MAPK1) can induce dormancy in differentiated cancer cells (99) as well as in CSCs (100). Similarly, the induction of the mammalian target of the rapamycin (mTOR) signaling pathway could preserve both the survival of dormant DCCs (101) and the quiescence of CSCs (102).

Strengthening these findings, more recently, the activation of mTOR was able to enrich the pool of CSCs within DCCs in bone marrow (BM) metastatic niches in prostate cancer models, through a mechanism involving the release of growth arrest specific 6 (GAS6) by osteoblasts (103). Along with this, the Notch and Wingless (Wnt) pathways, which are essential for the maintenance of cancer stemness (104-106), were proven to promote cancer cell reawakening in different solid tumors $(107,108)$. Notably, these pathways could promote cell cycle progression in a fashion dependent on the protooncogene cMyc, while their inactivation was associated with CSC senescence and tumor dormancy (109-112). Furthermore, c-Myc could trigger the polycomb repressor complex 1 component (PRC1) Bmi-1 expression, which in turn seems to correlate with breast cancer patient relapse years after treatment (113) and to influence the self-renewal capability of breast CSCs (114). Other examples proving the molecular similarity between dormant DCCs and CSCs include the interleukin 6 (IL-6) cytokine leukemia inhibitory factor (LIF)-LIF receptor (LIFR) axis, which appears to have a role in preserving both dormancy and cancer stemness, at least in the breast cancer setting (115). Autophagy, an evolutionarily conserved process through which cells survive metabolic stress conditions (116), can regulate the survival of dormant cancer cells and CSCs (117-120).

Finally, mechanical cues of the ECM and the epithelial-tomesenchymal transition (EMT) process, may be functionally important for inducing stem traits in cancer cells and for promoting their metastatic outgrowth (121-123). For example, the Zinc Finger E-Box Binding Homeobox 1 (ZEB1), a key regulator of EMT, was shown to contribute to the cellular response to microenvironmental stimuli, such as local inflammation and the tumor promoter transforming growth factor- $\beta$ (TGF- $\beta$ ), by activating a transcriptional program that pushes DCCs out of dormancy, committing them with stemlike features $(124,125)$. Similarly, the hypoxia-induced lysyl oxidase like-2 protein (LOXL2) can promote EMT and endow breast cancer cells with the ability to switch from dormant nonCSCs into proliferating metastatic CSCs (123). In this context, analyses in colorectal cancer models have recently revealed that the EMT-related factor ZEB2 coordinates a program of therapy resistance of quiescent cancer cells (126). Of note, these cells, which pre-exist in therapy-naïve tumors, show recognizable stem-like traits and behaviors (126). On the whole, these findings suggest again that the binomial dormant DCCs and CSCs could be interchangeable.

However, not all CSCs are dormant (9); and not all dormant cells are CSCs (127). Dormant cancer cells likely comprise both CSC and non-CSC subpopulations (7). Moreover, CSCs do not necessarily retain dormant-like features owing to their capacity to switch from dormant to proliferative states (128). Based on their tendency to enter dormancy, cancer (stem) cells can be broadly grouped into (i) dormancy-competent CSCs, (ii) dormancyincompetent CSCs, (iii) cancer repopulating cells, and (iv) DCCs $(7,129)$. Dormancy-competent CSCs are endowed with the ability to switch between dormancy and reawaking states, a plasticity that fosters their metastatic potential and resistance to therapy $(7,129)$. Conversely, dormancy-incompetent CSCs are usually enriched in advanced diseases and are characterized by a loss in the ability to enter dormancy, possibly due to the progressive accumulation of somatic mutations in the mechanisms governing dormancy entry $(7,129)$.

Indeed, as the tumor progresses and the microenvironment evolves, CSCs accumulate epigenetic and genetic alterations despite their robust DNA damage response (130), and dormancycompetent CSCs may turn into dormancy-incompetent CSCs (129). Cancer-repopulating cells are the subset of CSCs able to self-renew post-therapy and thus responsible for relapse and metastatic onset $(7,129)$. Finally, DCCs, either with stemlike or differentiated features, lie in secondary distant organs and the bloodstream (in this latter case, acting as CTCs) and preserve the ability to reawaken and fuel metastatic outgrowth $(7,129)$.

As above described, striking parallels exist between dormant DCCs and dormant CSCs. These analogies also apply to the microenvironmental cues, encompassing biological, biochemical, and biophysical factors, that coordinate both DCC outgrowth and CSC self-renewal. Further research in this area could uncover new similarities that ultimately may offer therapeutic solutions for unmet medical needs. 


\section{MICROENVIRONMENTAL CUES COOPERATE TO TIP THE BALANCE BETWEEN CANCER DORMANCY AND REAWAKENING}

The TME is a complex and dynamic ecosystem made up of a heterogeneous population of cancer cells and resident or infiltrating non-cancer cells [mainly leukocytes, including lymphocytes and tumor-associated macrophages (TAMs), cancer-associated fibroblasts, endothelial cells, and pericytes]. These are surrounded by the ECM and a mixture of secreted molecules encompassing lymphokines, cytokines, growth factors, and metabolites, among others. Cancer cell behavior and fate are profoundly influenced by the constant and evolving interplay with microenvironmental players, which often corrupt cancer cells to survive and eventually give rise to overt disease. The TME thus represents the background where physical and chemical perturbations tip the balance quiescence vs. proliferation. Quiescence and proliferation, in turn, come into sharp focus as by-products of the co-evolution of cancer cells and their microenvironments. Indeed, it is emerging that, in response to mitogenic and stress-signaling pathways, cancer cells trigger a set of complex intracellular molecular programs, thus underscoring a situation in which intrinsic mechanisms perfectly meet the cooperative action of extrinsic factors (3). Such intrinsic molecular pathways are beyond the scope of this review and have been extensively reviewed elsewhere (131-134). In this review, we will only cover the different microenvironmental cues governing dormancy regulation, with particular emphasis on CSCs and metastatic outgrowth.

\section{Cancer Niches: More Than Just Fertile Soils}

Niches are specialized areas of the TME that regulate cancer (stem) cell fate and properties by the joint action of cellcell and cell-ECM crosstalks and the messages delivered by paracrine factors.

Metastatic niches are the fertile environments of secondary organs (i.e., BM, lymph nodes, lungs, liver, and brain) that provide favorable conditions for the seeding of DCCs with stem-like and non-stem-like features (135). Indeed, metastatic niches guarantee the nutrient and oxygen supply required for cell proliferation, thus setting the point for cancer (stem) cell proliferation or quiescence (135).

A body of evidence indicates that the BM frequently hosts DCCs derived from different primary organs, including breast, colon, prostate, head, and neck (136), although these DCCs rarely develop bone metastases (137). This observation suggests that BM metastatic niches could delay or even prevent tumor mass sprouting by inducing a state of dormancy (138), a situation observed in expanded hematopoietic stem cells (HSCs) undergoing differentiation (139). In line with this hypothesis, metastatic niches reportedly provide unique signals promoting quiescence and long-term survival. For example, Notch2, which is known to induce cancer cell proliferation in primary breast carcinomas (108), was recently shown to have an opposite effect in metastatic BM niches, favoring the quiescence and long-term survival of disseminated breast CSCs (140).

The Wnt pathway, which in its canonical form acts as a regulator of processes like cell proliferation and cell stemness (141), is also inversely associated with cancer cell dormancy $(107,142)$, was reported to induce dormancy of prostate cancer cells populating the $\mathrm{BM}$ niches, via a mechanism involving the non-canonical receptor tyrosine kinase-like orphan receptor 2 (ROR2)/Siah E3 Ubiquitin Protein Ligase 2 (SIAH2) signal, resulting in the inhibition of the canonical Wnt/ $\beta$-catenin pathway (143). In this study, a negative correlation between ROR2 expression and metastasis-free survival in patients with prostate cancer was observed, potentially offering new potential therapeutic opportunities. These data are in line with previous observations of a role for non-canonical Wnt signaling in maintaining HSCs in a quiescent $\mathrm{G}_{0}$ state (144). At odds with this is the fact that canonical Wnt signaling, out of the $\mathrm{BM}$, is generally inversely associated with cancer cell dormancy in different tumor types $(107,142)$. On the whole, these observations show opposite effects led by the same factors in different metastatic niches, where they likely face different microenvironmental factors. This further supports the hypothesis that HSC niches may host dormant cancer cells.

Other microenvironmental signals involved in dormancy at the metastatic site include TGF- $\beta$, bone morphogenetic proteins (BMPs), and LIFR. Firstly described as a potent inhibitor of HSC proliferation $(145,146)$, TGF- $\beta$ is now recognized as another major factor that, once released by osteoblasts (one main BM stromal cell type), keeps DCCs and CSCs in a state of protracted dormancy $(147,148)$. This effect mainly relies on the triggering of the Gas6 receptor Axl (148) and the downstream activation of the p38 MAPK signaling (147). Similarly, the production of BMPs by BM stromal cells was associated with DCC hibernation. Specifically, the presence of BMP7 induced dormancy of prostate CSCs by activating the MAPK p38, and by fostering the expression of the cell cycle inhibitor p21 and the metastasis suppressor gene $\mathrm{N}$-myc downstream-regulated gene 1 (NDRG1) (100). Accordingly, a variant of BMP7 (BMP7v) reportedly halted the metastatic spreading of colorectal CSCs by inhibiting the EMT program and by forcing cancer cell differentiation (149). In line with these observations, blocking BMP ligands via the TGF- $\beta$ inhibitor Coco reawakened dormant breast CSCs and favored disease outgrowth in lung niches, which are known permissive soils (150). Notably, in a large cohort of patients, Coco-related metagenes predicted metastatic relapse in the lung, but not in the BM nor the brain, suggesting that Coco could be an organ-specific regulator (150). Finally, in breast cancer patients, low LIFR levels were shown to correlate with poor prognosis and with the appearance of overt metastasis along with the loss of CSC-associated genes (115). This is in line with previous observations which indicate that IL-6 plays a role in reawakening breast CSCs from therapy-induced dormancy (151).

Beyond reacting to soluble factors, DCCs also engage with other cell types of the metastatic niche, as well as with the ECM. Experimental studies show that breast cancer cells prime mesenchymal stem cells (MSCs) residing in BM niches to transfer microRNAs (miRNAs) via exosomes, which in turn 
promote cancer cell quiescence and drug resistance (152, 153). Apparently at odds with these observations, using a 3D co-culture model, Bartosh et al. demonstrated that DCCs from breast tumors cannibalize surrounding MSCs, resulting in an increased survival and tumor mass dormancy (154). Osteoblasts and osteoclasts, which are BM stromal cells with opposite physiological functions (155), also play opposite roles in the regulation of DCC dormancy. This was shown in myeloma DCCs, which entered dormancy while engaging with osteoblasts in the endosteum, while they started proliferating (i.e., reawakened) upon interaction with osteoclasts (77). Accordingly, as reported above, in a prostate cancer model, osteoblasts induce mTOR signaling by releasing GAS6, and this preserves CSC dormancy (103). Moreover, in breast cancer models, osteoclasts were recruited in the proximity of DCCs, supporting DCC growth into overt metastases (156). At the molecular level, cancer cell reawakening appears dependent on soluble receptor activator of nuclear factor- kappa B Ligand (sRANKL) signaling (77).

Accordingly, in breast cancer models, osteoclasts were found to be recruited in the proximity of DCCs and to support their growth into overt metastases (156). Along with this, a recent study in lung metastatic niches demonstrated that sustained inflammation and the interaction of DCCs with immune cells promote the formation of neutrophil extracellular traps (NETs, networks of neutrophil-derived extracellular fibers) in turn driving the switch from dormancy to reawakening (157). This effect was associated with the activity of neutrophil elastase and matrix metalloproteinase 9 (MMP9), two NET-associated proteases which sequentially remodel the ECM and activate the integrin $\alpha 3 \beta 1$ on cancer cells, eliciting downstream mitogenic signaling culminating in cellular dormancy.

The perivascular niche, a tumor promoting milieu made up of a multitude of microvessels, regulates dormancy of cancer cells disseminated into $\mathrm{BM}$, the lungs, and brain from various primary tumors $(48,158-160)$. Perivascular niches are characterized by the high availability of oxygen, nutrients, and paracrine factors, which renders them a permissive environment for the proliferation of DCCs and CSCs $(161,162)$. Accordingly, distinct types of CSCs and DCCs localize in the perivascular niches, growing in the proximity of capillaries $(97,163)$. It recently emerged that bidirectional interactions between these cells and components of the perivascular niche, including endothelial cells, are relevant for tumor evolution. The pool of glioblastoma CSCs residing at perivascular niches were shown to engage integrin $\alpha 7$-laminin interactions that foster invasiveness as well as selfrenewal and growth potential (164), all features correlating with a dismal prognosis (165). Moreover, breast cancer cells that infiltrate lung metastatic niches induced the expression of the matricellular protein periostin (POSTN) in endothelial cells. In turn, POSTN contributed to CSC survival, nurturing micro to full macrometastases via a mechanism dependent on the activation of the Wnt signaling (166) and the activity of TGF- $\beta 1$ (48). Other ECM components of the perivascular niche that influence metastasis include osteopontin and tenascin C (167-169). Emerging evidence indicates that these proteins act as primary regulators of CSC survival, self-renewal, and reawakening via the activation of transcriptional programs centered on Wnt, Nanog, and POU domain, class 5, transcription factor 1 (POU5F1, best known as Oct-4) (167-169).

Of note, is the fact that there is a certain degree of heterogeneity in endothelial cells of the perivascular niches. Thus, while endothelial cells of the sprouting neovasculature were shown to foster metastatic outgrowth, those of stable microvasculature mostly preserved and promoted cancer cell dormancy through the tumor suppressor thrombospondin1 , acting as a rate-limiting step for disease re-occurrence (48). Moreover, dormant and proliferating breast cancer cells displayed a distinct localization in perivascular areas (160). More precisely, dormant cells were shown to reside predominantly close to perisinusoidal venules expressing high levels of the inflammatory vascular cell adhesion molecule E-selectin, which favors the entry of cancer cells into the BM, and of the stromal cell-derived factor 1 (SDF-1), which anchors cells to the niche through its interaction with the $\mathrm{C}-\mathrm{X}-\mathrm{C}$ chemokine receptor type 4 (CXCR4), respectively (160).

\section{The ECM: A Biochemical and Biophysical Niche for Cancer Cells}

The ECM, commonly defined as the non-cellular component of a tissue, is a highly dynamic and physiologically active structure, that provides biochemical and biophysical support for surrounding cellular components (170). Characterized by a continuous remodeling over space and time, the ECM also represents a biological barrier, an anchorage site, and a movement track, playing major roles in regulating cellular interactions and communications (170). The ECM is tightly organized during embryogenesis and tissue homeostasis, but becomes extremely deregulated and deranged in cancer (171).

Emerging evidence suggests that the ECM may serve as a niche for DCCs and CSCs, influencing cell survival and proliferation, and thus dormancy $(171,172)$. Thus, downregulation of the urokinase plasminogen activator receptor (uPAR), which is involved in cell/ECM interactions, affected the capability of head and neck squamous cell carcinoma cells to interact with integrins, in turn causing deactivation of mitogenic pathways and induction of dormancy (173). Along with this, tissue stiffness (a mechanical property of the TME) and its underlying mechanotransduction pathways are also involved in tumor progression and metastasis $(122,174)$. Thus, in breast cancer models, the crosslink between fibrosis-associated deposition of type I collagen and integrin $\beta 1$ or lysyl oxidase (LOX), was described to create a growth-permissive microenvironment capable of reawakening DCCs, thus supporting proliferative metastatic growth $(46,175)$. This occurred through the activation, downstream of integrin $\beta 1$, of players including focal adhesion kinase (FAK), non-receptor tyrosine kinase (Src), ERK, and myosin light chain kinase (MLCK) (46). In this context, there is interesting evidence that pharmacological co-inhibition of Src and MEK1/2 prevented disease recurrence by killing dormant breast and ovarian DCCs $(176,177)$. Similarly, interstitial collagen I was described to favor the interaction between the tetraspanin Transmembrane 4 L Six Family Member 1 (TM4SF1) and the collagen receptor tyrosine kinase Discoidin domain 
receptor family, member 1 (DDR1). This led to the expression of the stem related factors SRY (sex determining region Y)-box 2 (SOX2) and NANOG, driving multiorgan metastatic reactivation in the lung, bone, and brain (178).

The dormant-to-proliferative metastatic switch is also favored by a global reconfiguration of the cytoskeletal architecture of DCCs often mediated by the integrin $\beta 1$ signaling. Thus, using a model of lung disseminated breast cancer cells, Green et al., demonstrated that, cancer cells respond to integrin $\beta 1$ mediated fibronectin production and signaling by activating MLCK, resulting in the generation of actin stress fibers and entry into a proliferative state (179). The ability of integrin $\beta 1$ signaling to promote cell-cycle progression seems also to rely on FAK activation (180). In particular, Weinberg's team showed that soon after extravasation into the lungs, breast cancer cells arrest their proliferation due to their inability to engage stable adhesions with ECM components. Later on, some cancer cells acquiring an elongated morphology developed abundant cellmatrix adhesion plaques, which in turn triggered the integrin $\beta 1-F A K$ signaling and promoted exit from dormancy (180). Src family kinases (SFKs) also act downstream the integrintriggered dormant-to-proliferative switch (176). Moreover, using an in vitro model of stiff-soft tunable matrix it was revealed that fibrosis related integrin $\beta 1$ and FAK signaling increased mitogenic stimuli by inducing protein kinase $\mathrm{B}(\mathrm{PKB} / \mathrm{Akt})$ and signal transducer and activator of transcription 3 (STAT3). In this setting, only cells grown in soft matrix supports expressed CSC markers (181), suggesting that a pliable microenvironment might support cancer cell stemness, a hypothesis that is intriguing but which still requires in vivo validation. Finally, the association between matrix stiffness and cancer cell proliferation appears to be influenced by endothelial cells (182). More precisely, in a stiff environment, endothelial cells express the matricellular protein cysteine-rich angiogenic inducer 61 (CYR61), which in turn induces a $\beta$-catenin-dependent upregulation of $\mathrm{N}$-cadherin levels. This lets cancer cells stably interact with the endothelium and thus enter the bloodstream and metastasize (182).

To add further layers of complexity, a recent study demonstrated that a stiff matrix could also induce dormancy (183). In this study, cancer-repopulating cells, when coping with a harsh environment, activate an epigenetic program that leads to the transcription of ten-eleven translocation 2 (Tet2) hydroxymethylating enzyme. Tet2, in turn, activates the cell cycle suppressors p21-p27 and induces integrin $\beta 3$ downregulation, respectively, promoting and preserving dormancy (183). Moreover, a recent deep single cell analysis revealed a high phenotypic heterogeneity in dormant cancer cells, encompassing pools of quiescent, senescent, and actively proliferating cells (184). The characterization of cells entering long-term dormancy demonstrated that these cells adhere stably to a stiff matrix through integrin $\alpha 5 \beta 1$ and rho-associated kinase (ROCK)-mediated cell tension. Moreover, the capability to exit from dormancy appears strictly connected to the ability to trigger MMP-mediated FN1 degradation (184).

In conclusion, disseminated cancer (stem) cells and their environment engage in an intricate molecular cross-talk, regulating the entry into and the exit from dormancy and thus determining cancer cell fate (Figure 2).

\section{ANGIOGENIC SWITCH AND ANGIOGENIC DORMANCY}

A hallmark of progressive cancer growth, in both primary and secondary tumors, is the induction of tumor vasculature, a process termed the "angiogenic switch" $(185,186)$. Indeed, like healthy tissues, tumors need both an appropriate supply of oxygen/nutrients and a way to remove waste products (187). However, unlike physiological angiogenesis, in which new vessel sprouting is a highly regulated and self-limited process, tumor angiogenesis lacks growth controls resulting in continuous and deregulated vessel production (185). This leads to a structurally and functionally abnormal tumor vascular network characterized by new vessels with dead ends, which results in low oxygen tension (hypoxia), the paucity of metabolites, and imbalanced expression of angiogenic factors. This latter eventually stimulates further abnormal angiogenesis (185). As neovascular supply is crucial for tumor growth, cancer cells, including those integrated into the vessel walls (188), undergo adaptive dormancy, also known as angiogenic dormancy $(186,189)$. During angiogenic dormancy, cancer cell proliferation rate is balanced by enhanced apoptosis induction. This equilibrium maintains tumors that are microscopic and undetectable, for extended times (12).

Currently, there are three subtypes of hypoxia and related cancer cell adaptive mechanisms (190). First, acute hypoxia is characterized by transient perturbation in perfusion lasting from a few minutes up to a few days. Reportedly, cancer cells facing acute hypoxia decrease oxidative metabolism and activate autophagy, yet retaining high proliferative potential (191-193). Second, chronic hypoxia is mainly related to the presence of abnormal neo-vessels, leading to limited perfusion and oxygen supply. This long-lasting phenomenon is linked to a state in which cancer cells remain persistently dormant (192). Finally, cycling hypoxia is characterized by oxygen fluctuations in parallel with intermittent phases of cancer cell dormancy and reawakening that have been associated with increased tumor aggression $(190,194)$.

The balance between the angiogenic switch and angiogenic dormancy is a finely-tuned process regulated by integrated microenvironmental factors, including the pro-angiogenic vascular endothelial growth factor (VEGF), platelet-derived growth factor (PDGF), anti-angiogenic thrombospondin-1, angiostatin, and endostatin (189). Prosaposin has been described as another regulator of metastatic growth arrest (195). Once produced by cancer cells, prosaposin acts in a paracrine and endocrine fashion inducing the expression of thrombospondin-1 in stromal cells at primary and distant tumor sites, which blocks neoangiogenesis and delays tumor growth (195). Many niche components also play a role in regulating angiogenesis. Indeed, CSCs, seem able to transdifferentiate and directly contribute to the formation of abnormal vessels, thus supplying for the absence of true angiogenesis $(196,197)$. Moreover, CSCs often promote a considerable enhancement of VEGF levels, both by a 


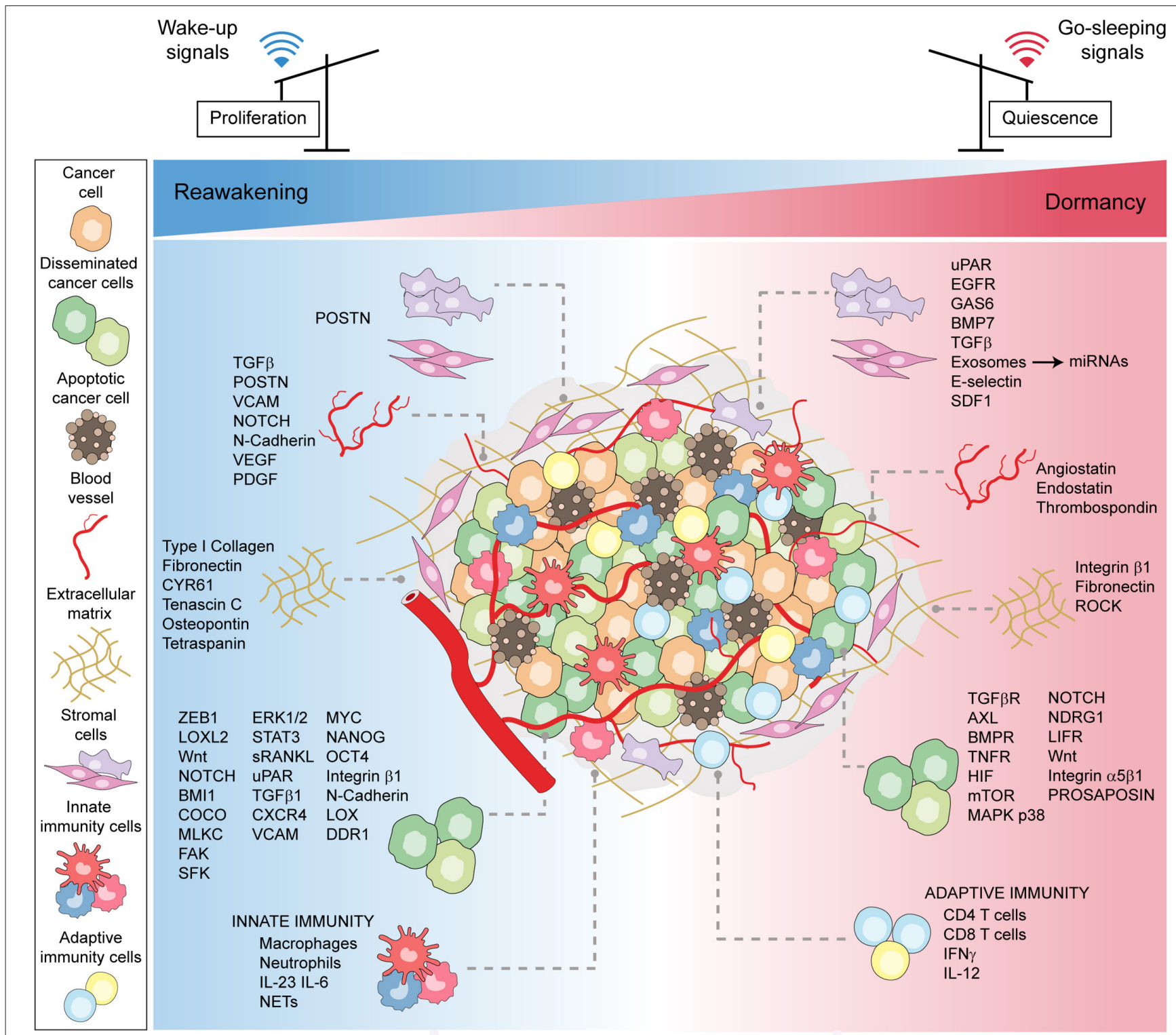

FIGURE 2 | Microenvironmental patterns tuning cancer dormancy, reawakening, and stemness. A schematic model showing the plethora of microenvironmental cues, encompassing the cellular, molecular, and physical factors, that converge to induce either stress-related or mitogenic signals to cancer cells. The bulk of cancer cells, encompassing disseminated and stem cells, in the face of contextual signals, either enter or exit dormancy.

direct production and by stimulating a pro-angiogenic activity in stromal cells localized in the proximity of the niche (198-200). Along with this, some stem-related factors such as Notch also act as angiogenesis promoters $(201,202)$, while anti-angiogenic factors (i.e., thrombospondin-1) are associated with inactivation of the stem-related transcriptional factors (i.e., MYC) (203), which in turn promote dormancy (109). Of note is the fact that CSCs adopt further adaptive mechanisms to cope with hypoxia, among which the expression of the hypoxia-inducible factors (HIFs) and HIF-regulated genes (204) that induce cellular dormancy by activating p21 signaling (205). In a seminal work, Almog et al. characterized a transcriptional rewiring of cancer cells undergoing an angiogenic switch (206). This switch was associated with downregulation of the angiogenesis inhibitor thrombospondin and upregulation of genes not hitherto linked to tumor dormancy, such as endothelial cellspecific molecule 1 (ESM1), 5'-ectonucleotidase, tissue inhibitor of metalloproteinase 3 (TIMP3), epidermal growth factor receptor (EGFR), insulin-like growth factor receptor (IGF1R), phosphatidylinositol 3-kinase (PI3K) signaling, Eph receptor A5 (EphA5), and histone H2BK (206).

In summary, these myriad microenvironmental components and their reciprocal interactions, represent the major culprits governing cancer (stem) cell dormancy and outgrowth, and 
are a clear index of the complexity of this regulation, offering additional potential targets for therapeutic intervention.

\section{CANCER (STEM) CELL DORMANCY AND IMMUNITY: PRODUCTIVE DIALOGS AND RECIPROCAL REGULATIONS}

\section{Immune-Induced Dormancy: the Equilibrium Phase of Cancer Immunoediting}

Over the past two decades, understanding of tumor biology has increased and revealed that the host immune system plays a dual role in cancer: it may both constrain and paradoxically aid tumor outgrowth. This phenomenon, which has been referred to as cancer immunoediting, passes through three phases, namely elimination, equilibrium, and escape (207).

During the elimination phase or immunosurveillance, cancer cells that escaped intrinsic control are destroyed by extrinsic, immune-mediated tumor suppressor mechanisms (208). The successful completion of this phase ensures cancer cell clearance and prevents the onset of the clinically apparent disease. However, rare cancer subclones may survive and progress into a phase of equilibrium, during which the immune system, by inducing a functional state of dormancy, might contain but not fully extinguish cancer cell growth. Of note, is the strong and relentless pressure exerted by the immune system during this phase, which may either control the outgrowth of occult tumors throughout the life of the host or sculpt less immunogenic variants that ultimately evade immune attack (208). Such immunoedited cancer cells, that are no longer susceptible to immune control, progress in the escape phase, emerging into clinically visible tumors (208). Of the three phases of cancer immunoediting, equilibrium is probably the longest and the most difficult to characterize. Clinical evidence on the existence of an equilibrium or tumor-dormancy phase came from the unintentional transmission of cancer from transplant organ donors to immunosuppressed recipients. In these cases, donors either were in durable clinical remission (209-211) or had no known history of malignancy $(212,213)$. Notably, cases of the rapid outgrowth of occult metastases were even reported when donors had glioblastoma, which usually does not metastasize (214). Similarly, metastatic recurrence of primary renal cell carcinoma soon after the post-transplant immunosuppressive medication was reported (215). These observations suggest a mechanism of immune-mediated control for occult malignancies and a progressive outgrowth of cancer cells under pharmacologically-induced immunosuppression, a condition required to prevent the recipient's rejection of the organ. The median time frame between transplantation and metastasis detection is relatively short, ranging between 3 and 36 months, with no differences between cancer types and the organ transplanted (211). As metastases generally take 6 to 12 years to emerge (35), it is plausible that under immune suppression, adaptive immunity cannot hold dormant cells in check, which thus exit from the equilibrium/dormant/persistent state (13). In line with these observations, in a variety of human tumors, it was reported that a 20 to 50 year interval from initial carcinogen exposure to the clinical detection of disease. Moreover, epidemiologic studies in autopsies revealed that microscopic foci of disease frequencies considerably exceed clinical incidence rates in various cancer types (e.g., thyroid cancer, prostate and breast carcinoma) (216-218). This gets stronger during the theoretical existence of periods of subclinical dormancy during tumor progression (219). However, none of these reports visualized tumor dormancy de facto, and they did not describe the immune effectors involved. Admittedly, clinical cancer dormancy is still poorly characterized and the role of innate and adaptive immunity in initiating and then stabilizing the dormant state is a matter of debate (220). However, we have strong evidence supporting the existence of an equilibrium phase governing clinical cancer dormancy. Indeed, tumors may chronically persist without symptoms for years and even decades before recurring either locally or at distant metastatic sites (4, $25,221)$. Moreover, late relapses are relatively frequent in breast and prostate carcinoma patients after radical surgery $(222,223)$, in melanoma, thyroid and renal cell carcinoma $(224,225)$, nonHodgkin's lymphoma (226), and acute myeloid leukemia (227).

In parallel, clinical and experimental studies have provided evidence that cancer cells can disseminate during premalignant stages of the disease, thus entering a protracted period of metastatic dormancy into target organs (35). Early preclinical suggestions of the capability of the immune system to hold cancer cells in a dormant/equilibrium phase were provided by transplant experiments in which immunodeficient mice adoptively transferred with $\mathrm{T}$ cells and then challenged with the murine B lymphoma BCL1 cells, were endowed with the capability to induce and maintain a state of tumor latency (228). Similarly, BCL1 dormant cancer cells resident in the spleen of immunized mice showed no evidence of disease 250 days after tumor rechallenge (229). In line with these findings, the adoptive cell transfer of tumor specific lymphocytes provided long-term protection from tumor development, retaining minor foci of dormant cancer cells on mouse models of prostate cancer (230) and lymphomas (231). Additional studies with mouse models of skin malignancies confirmed that the immune system may induce long-term latency of occult primary and metastatic carcinomas $(232,233)$. These findings are consistent with a role for anti-tumor immunity, and in particular $\mathrm{T}$ cells, in the maintenance of an equilibrium dormant state preventing tumor-cell growth. Pivotal studies from Schreiber's lab have further provided evidence and unveiled mechanisms of immune mediated dormancy. It was observed that the treatment of mice with low-dose methylcholanthrene (MCA) was followed by the development of aggressive tumors in only a few animals, with a sizeable percentage of the surviving mice free of disease. Deceptively, however, these mice bear dormant tumors that were held in check by the immune system. Indeed, when animals were treated with antibodies blocking $\mathrm{T}$ lymphocytes or neutralizing the cytokines IL-12 or interferon- $\gamma$ (IFN- $\gamma$ ), tumors were released from immune control and outgrew (13). These findings validate previous observations of dormancy induced by CD8 T cell derived factors $(228,234)$. Moreover, MCA-induced sarcomas from immunodeficient mice were more immunogenic 
than those arising in immunocompetent hosts (235). Follow-up studies showed opposing, complementary roles for ILs, during the equilibrium phase. Specifically, IL-23 seemed to promote the survival and outgrowth of occult cancer cells, while IL-12 seemed to favor dormancy and thus prevent immune escape (236). At odds with previous reports, innate immune signaling is associated with the awakening of dormant cancer cells. Local inflammation in the lungs was shown to ignite the exit of DCCs from latency, and thus the growth into overt metastases through the activation of a previously silent EMT transition program (125). This provided a newfound knowledge of the dual role of the immune system in protecting the host against tumor outgrowth and in sculpting the immunogenic profile of evolving tumors, finally rendering them more fit to survive and progress in an immunocompetent environment (235).

On the whole, these observations suggest that immunity can maintain cancer cells in a transient dormant state, which as a matter of course, end in either tumor elimination or tumor escape. CSCs may play pivotal roles in preserving the cancer dormant state. Indeed, they cope with robust anticancer immune responses by subverting immune effector functions and by drastically reducing their visibility (237). At the same time, however, such an immunopriviledge may foster immune escape and cancer outgrowth (238). It remains to be elucidated whether immune-mediated dormancy is either always a matter of a bulk tumor or may also resemble cellular dormancy. Mining the mechanisms regulating immune-mediated tumor equilibrium will help solve this question, and will open the possibility of uncovering predictive signatures with invaluable prognostic and therapeutic implications.

\section{Dormancy as a Mechanism of Immune Escape: Sleeping in the Name of Survival}

Immune escape is central to tumor persistence and relapse. Dormant cancer (stem) cells constitute the most critical, yet heterogeneous fraction of malignant cells able to evade host antitumor immunity $(6,7)$. Effective mechanisms of escaping immune control are (i) prevention of immune detection, (ii) prevention of immune activation, and (iii) activation of immune suppression $(239,240)$.

The immunogenicity of a tumor relies on a combination of antigenicity, i.e., the expression and presentation of tumorassociated antigens, and adjuvanticity, i.e., the release of alarmins and damage signaling (241). Cancer cells defective in either antigen presentation or production of adjuvant-like signals (or both) remain relatively invisible to the immune system and escape immune detection. The capability of dormant cancer cells to evade immune surveillance by reducing antigenicity has been reported $(242,243)$ and more recently confirmed through clinical immunogenomics $(244,245)$. Downregulation of the major histocompatibility complex class I (MHC-I) was ostensibly observed in quiescent cancer cells and CSCs isolated from different cancer types $(238,246)$. In a model of liver disseminated pancreatic cancer, dormancy-related loss of MHCI was attributable to unresolved endoplasmic reticulum stress, and was responsible for hiding and protecting DCCs from $\mathrm{T}$ cell-mediated surveillance (247). Interestingly, the observation that, in hair follicles, Lgr5-GFP stem cells survive the adoptive transfer with antiGFP $\mathrm{T}$ cells by persisting in a dormant state, and reducing the expression of MHC-I molecules (248), further confirms that loss of antigen presentation is a common mechanism in quiescent cells, which CSCs adopt to escape immune attack. If the tumor does not manage to escape detection, then it can evolve to prevent the activation of a robust anticancer immune response. The immunosuppressive effects of cancer cells are mediated by (i) the secretion of soluble factors, (ii) the expression of inhibitory molecules, and (iii) the turning of infiltrating leukocytes into tolerogenic cells that, in turn, can suppress other tumor-specific immune cells. In a model of acute myeloid leukemia, the expression by cancer cells of the immune checkpoints CD274 (best known as PD-L1) and CD80 (also known as B7.1) prevented $\mathrm{T}$ cell activity and preserved cancer dormancy (62). Furthermore, the microenvironment itself can help quiescent cells elude immune control. Indeed, within the perivascular niche, the activity of effector T cells can be inhibited through the release of immune suppressive cytokines (such as IL6 ) and the activation of the programmed cell death 1 (PDCD1, best known as PD1)-PD-L1 axis (249-251). In addition, tumor evolution seems to select for cancer cell clones resistant to the death effector mechanisms of the immune system. We recently discussed the genetic inactivation of the oncosuppressor caspase 8 (CASP8) and the death receptor FAS as strategic mechanisms cancer cells may adopt to evade apoptosis-mediated eradication by immune cells, mainly T and natural killer (NK) cells (5). These reports are in line with previous observations of dormant cancer cell-mediated escape from $\mathrm{T}$ cell induced apoptosis through deregulation of the suppressor of cytokine signaling 1 (SOCS1) cascade and overexpression of the pro-tumorigenic cytokine IL-3 (252).

Cancer cells defective for MHC-I molecules are optimal targets for NK cells, in which activation is MHC-unrestricted (253, 254). Evidence of evasion from NK mediated immunosurveillance by quiescent disseminated CSCs firstly came from Massague's lab. This team showed that by overexpressing the WNT inhibitor Dickkopf-related protein 1 (DKK1), CSCs enter a self-imposed quiescent state and downregulate the expression of UL16 binding protein (ULBP) ligands for NK cells, thus evading innate immunity and remaining latent in the long-term (255).

Additionally, dormant cancer (stem) cells may enter immune protected niches (also called immune-privileged niches), where they lie quiescent for extended periods (256). The capability of dormant niches to protect (cancer) stem cells from immune control is mainly due to the recruitment of regulatory immune cells, encompassing regulatory $\mathrm{T}\left(\mathrm{T}_{\mathrm{REG}}\right)$ cells, myeloid-derived suppressor cells (MDSCs), and immunosuppressive TAMs and neutrophils (TANs) $(257,258)$. In particular, TAMs are recruited by diverse chemotactic factors-including tumorderived colony-stimulating factor 1 (CSF1), vascular endothelial growth factor A (VEGFA), semaphorin 3A, CC-chemokine ligand 2 (CCL2), and CXC-chemokine ligand 12 (CXCL12)-and nullify the cytotoxic activity of $\mathrm{CD}^{+} \mathrm{T}$ cells by expressing the immune checkpoints PDL1 and B7-H4 $(259,260)$. 
In addition, TAMs and regulatory dendritic cells can recruit $\mathrm{T}_{\mathrm{REG}}$ cells and MDSCs, and foster their expansion and immunosuppressive functions (261-263). In brain metastatic loci, reactive astrocytes prevent $\mathrm{CD} 8 \mathrm{~T}$ cell activation and recruit TAMs through the signal transducer and activator of transcription 3 (STAT3) activation program (264). Similarly, once expanded and polarized under gamma delta $(\gamma \delta) \mathrm{T}$ cell control (265), TANs act as pro-tumorigenic players in particular in metastatic niches, conferring highly immunosuppressive properties to the TME through the release of leukotrienes (266).

Finally, some tumors seem to evolve and acquire the capability to corrupt and turn immune effectors against themselves, thereby causing immune cell death through mechanisms that physiologically limit the antitumor immune response $(240,267$, 268). These immune escape mechanisms can act in combination and make the tumor a formidable foe for the immune system, ultimately fostering the neoplastic outgrowth. Current integrated and single-cell based approaches that have been adopted to mine the immunome of primary and metastatic tumors seem extremely powerful, and may offer data that will soon implement the list of factors, cells, and mechanisms involved in immune escape.

\section{Clinical Detection of Dormant DCCS and CTCS}

The identification and possible targeting of dormant DCCs which persist during MRD is of utmost importance to prevent disease recurrence. However, the clinical detection (and monitoring) of cancer dormancy is a challenge, making it difficult to validate the cancer dormancy model in patients. Indeed, per definition, cancer dormancy is a controlled chronic disease that persists without any symptom or sign until its underlying equilibrium is disturbed and local or systemic relapse occurs. Two major obstacles need to be overcome for the clinical detection of cancer dormancy. First, micrometastatic, dormant DCCs are almost undetectable using conventional high resolution, wholebody imaging tools. Second, the entire process involves a long time frame of disease latency. In the last two decades, a flurry of research efforts have focused on the identification and standardization of highly sensitive and specific assays to identify and characterize occult micrometastatic cancer cells, in particular, DCCs in BM aspirates, and CTCs in peripheral blood.

\section{The Current State of DCC and CTC Detection}

Three methods are commonly used to detect and quantify DCCs and CTCs in liquid biopsies: (i) immunocytochemistry (IHC)/immunofluorescence (IF) staining followed by bright field/fluorescence microscopy; (ii) multicolor flow cytometry (MFC); and (iii) real time-polymerase chain reaction (RTPCR). In this context, IHC and IF are the most widely used approaches as they provide the major advantage of evaluating and characterizing morphological criteria at a single-cell level $(269,270)$. On the contrary, MFC analyses are largely used to analyze biopsies from advanced stage metastatic cancer patients as they allow the rapid screening of tens of thousands of cells per second coupled with the possibility of isolating pure, viable cell subsets for further experimentation. As examples, isolated cells can be expanded either in vitro, by establishing primary cell cultures, or in vivo, by using xenograft models, and then used for functional analyses (271). A major drawback of these antibodybased technologies is the possibility of false positives, due to an "illicit" expression of markers in non-malignant cells-which can be the result of inflammation or injury (272), or even of the formation of chimeras by the fusion of cancer cells with immune cells (273) - and false negatives, due to the loss of marker expression (270). Finally, RT-PCR-based transcriptome analyses allow for the simultaneous and high sensitive detection of multiple factors, although the probability of false positive results due to contamination and amplification of transcripts from noncancer cells is high. Besides, the presence of degrading enzymes could also give rise to false negative results (274). In these experimental settings, as DCCs and CTCs are a few tens dispersed in millions-to-billions of hematopoietic cells per milliliter of BM aspirate or blood, prior enrichment approaches through density gradient centrifugation and/or immunomagnetic bead separation are mandatory (269).

\section{Markers of DCC and CTC Detection, Isolation, and Characterization}

As hematopoietic cells circulating in the peripheral blood and residing in the BM are mainly of mesenchymal origin, epithelial cancer cells from different solid tumors can be identified through epithelium-specific antigens such as (i) cytoskeletal-associated cytokeratins (CKs, in particular CK 8, 18, 19, and 20) (275, 276), (ii) surface adhesion molecules, such as the epithelial celladhesion molecule (Ep-CAM) (269), and (iii) growth factor receptors, such as the erb-b2 receptor tyrosine kinase 2 (ERBB2, best known as HER2) for breast cancer and the epidermal growth factor receptor (EGFR) for lung cancer. Moreover, to disseminate in distant anatomical sites, cancer cells lose cell-tocell adhesion molecules and enter the EMT process. Therefore, markers of EMT, such as vimentin, FN1, twist family bHLH transcription factor 1 (TWIST1), snail family transcriptional repressor 1 (SNAI1) and 2 (SNAI2, best known as SLUG) can be used to detect cancer dormancy $(277,278)$. As described above, DCCs can show stem cell features (7), such as the expression of cell surface adhesion receptor CD44, the cell surface CD24, prominin (best known as CD133), and CD49 antigens, and the functional marker aldehyde dehydrogenase 1 family member A1 (ALDH1) (279). Notably, co-staining with specific markers helps discriminate between quiescent and actively proliferating DCCs and CTCs. The most common dormancy-specific markers are the lack of the nuclear antigen Ki67, and the expression of the nuclear receptor subfamily 2 group $\mathrm{F}$ member 1 (NR2F1), the basic helix-loop-helix family member e41 (BHLHE41, also known as DEC2), and the cyclin dependent kinase inhibitor $1 \mathrm{~B}$ (CDKN1B, best known as p27) (280). Because dormant cells activate cytoprotective programs (i.e., the UPR) to cope with environmental stresses, including hypoxia and glucose starvation, the expression of UPR proteins, such as the heat shock protein family A 
(Hsp70) member (HSPA5, best known as Grp78), can be analyzed (281).

\section{Major Limitations of DCC and CTC Detection and Future Directions}

Despite the successful detection and enumeration of DCCs and CTCs, and the unceasing development of automated and high sensitive analytical methodologies (e.g., CellSearch, ImageStream, FAST, Epic, CytoTrack, and EPISPOT platforms) $(270,282,283)$, achieving high yield and high purity remains a major challenge. Moreover, the high variability of the results is due to multiple reasons, including the heterogeneity of marker expression, the difficulties to recover intact and live cells, the bias of false positive and false negative data, and the lack of standardized protocols. This has prevented the implementation of DCC and CTC usage into the routine clinical practice (284288).

Currently, next-generation sequencing (NGS) multi"omics" technologies are providing large-scale data and more comprehensive characterization of the intricate molecular mechanisms underlying the hallmarks of cancer (289). The indepth knowledge of disease development, treatment resistance, and recurrence risk facilitated by this will be fundamental in guiding treatment decisions. Very recent advances in single-cell analyses have enabled researchers to characterize intra-tumor heterogeneity (i.e., the heterogeneity among the cancer cells of a single patient, at the spatial or temporal level), identify rare cell subsets, and measure the mutational landscapes of different cancer cell populations, and thus guide diagnosis and treatment. However, mainly due to the prohibitive costs (single-cell), multiomics analyses have not yet been implemented in the clinical setting, preventing the advancement of precision medicine. As there is a widely recognized need to detect and characterize dormant DCCs and CTCs in more detail, there will undoubtedly be a rapid development of new, standardized, and exploitable technologies in the near future, that will expedite DCC and CTC implementation in clinical settings to prevent relapse and thus improve outcome.

\section{IMPLICATIONS FOR THERAPY}

After years of bench studies on cancer dormancy, discoveries of the mechanisms regulating dormancy and reawakening could provide an opportunity for bedside translation. There are essentially two clinical options to target dormant cancer (stem) cells: (i) forcing them out of quiescence, so-called "lock-out" approaches, or (ii) sustaining their perpetual dormancy, socalled "lock-in" strategies $(138,290)$. Clinical trials were launched to study the safety and efficacy of both strategies (Table 2). Nonetheless, these strategies require detailed knowledge of the mechanisms underlying dormancy and tumor evolution, a clear view of which mechanisms are tissue-specific or instead common and thus universally exploitable, and the possibility/ability to stratify patients and distinguish those who could benefit from therapies targeting dormancy and those who could not.

As dormancy represents a mechanism by which cancer cells evade current conventional antiproliferative therapies, lock-out strategies aim at reawakening and forcing dormant cells into proliferation before treatment. According to this principle, exit from dormancy wakes up cancer cell sensitivity to conventional chemo and radiation therapy as well as some types of target therapy. Inhibitors of Polo-like kinase1 (Plk1), for instance, appear highly effective against proliferating colorectal CSCs (128). Notably, dormant CSCs survive the treatment with Plk1 inhibitors but retain sensitivity once out from quiescence (128). In patients with chronic myeloid leukemia and non-small cell lung cancer, ablation of F-box/WD repeat-containing protein 7 (FBXW7), a ubiquitin ligase that regulates dormancy by degrading cMyc and Notch (291), pushes CSCs out of dormancy and thus significantly enhances the benefit of imatinib and gefitinib, respectively $(292,293)$. Likewise, human leukemia stem cells efficiently exit the quiescent state and enter an active cell cycle following the administration of granulocyte colonystimulating factor (GCSF) and IFN- $\alpha(294,295)$. Proliferating stem cells are then vulnerable to cytarabine- and 5-fluoro-uracilbased chemotherapy $(294,295)$.

In a more recent study, inhibition of macroautophagy could force quiescent ovarian CSCs out of $\mathrm{G}_{0}$ and prevent further entry into quiescence (296). The dependence on specific niches (see above) represents a therapeutic opportunity for preventing or reducing metastasis outgrowth. This is exemplified by the targeting of E-selectin- and SDF-1 in the bone perivascular metastatic niche, which disrupts the anchorage of dormant breast cancer cells (160). This forces the mobilization of dormant cells into the bloodstream, where they are more vulnerable to chemotherapy, thus preventing metastatic colonization. Along similar lines, breaking the foothold of dormancy by targeting blood vessels, the ECM, or effector immune cells may prove effective in inhibiting dormant cancer cell survival and eventually relapse (297-299). Indeed, the blockade of the CCL2-C-C Motif Chemokine Receptor 2 (CCR2) axis, involved in breast cancer cell metastatic seeding in the lungs and recruitment of metastasisassociated macrophages (300), has provided therapeutic benefit in fibrosarcoma models (301). Similarly, inhibition of neutrophil infiltration by targeting the Notch1 signaling prevented lung metastatic spread of breast, ovary, and colorectal carcinoma, as well as melanoma (302). Overall, these pieces of evidence may offer new opportunities to specifically target DCCs and strategically eliminate MRD.

Data from clinical trials are emerging, and the results are promising (Table 2). As an example, in breast cancer patients docetaxel treatment following adjuvant fluorouracil, epirubicin, and cyclophosphamide (FEC) therapy successfully erased dormant DCCs (as detected in BM aspirates) while increasing the rates of metastasis-free survival [(303) NCT00248703]. Moreover, multiple on-going trials are exploiting immunotherapeutic protocols to target dormant cells. To reach a successful outcome, a few parameters have to be properly addressed. First, as dormant cancer (stem) cells develop early during tumor progression, their antigenic 
TABLE 2 | Clinical trials targeting the dormancy window in cancer patients.

\begin{tabular}{|c|c|c|c|c|c|c|}
\hline Description & $\begin{array}{l}\text { ClinicalTrials.gov } \\
\text { identifier }\end{array}$ & Drug(s) & $\begin{array}{l}\text { Number of } \\
\text { patients }\end{array}$ & $\begin{array}{l}\text { Recruitment } \\
\text { status }\end{array}$ & Phase & Results \\
\hline $\begin{array}{l}\text { Pilot study to evaluate the impact of } \\
\text { Denosumab on DTCs in patients with } \\
\text { early stage breast cancer }\end{array}$ & NCT01545648 & Denosumab & 4 & $\begin{array}{l}\text { Terminated } \\
\text { (low accrual) }\end{array}$ & 2 & $\mathrm{~N} / \mathrm{A}$ \\
\hline $\begin{array}{l}\text { Pilot study of mobilization and } \\
\text { treatment of DTCs in men with } \\
\text { metastatic prostate cancer }\end{array}$ & NCT02478125 & $\begin{array}{l}\text { Burixafor hydrobromide, } \\
\text { G-CSF, Docetaxel, or in } \\
\text { combination }\end{array}$ & 3 & $\begin{array}{l}\text { Terminated } \\
\text { (low accrual) }\end{array}$ & 1 & $\mathrm{~N} / \mathrm{A}$ \\
\hline $\begin{array}{l}\text { Effect of Trastuzumab on DFS in early } \\
\text { stage HER2-negative breast cancer } \\
\text { patients with ERBB2 expressing } \\
\text { DTCs }\end{array}$ & NCT01779050 & Trastuzumab & 7 & $\begin{array}{l}\text { Active, not } \\
\text { recruiting }\end{array}$ & 2 & $\begin{array}{l}\text { All patients experienced } \\
\text { eradication of } \\
\text { HER2/neu-positive ITCs } \\
\text { from bone marrow; } \\
\text { reduction in the number of } \\
\text { ITC-positive patients }\end{array}$ \\
\hline $\begin{array}{l}\text { Zoledronic acid in the treatment of } \\
\text { breast cancer with minimal residual } \\
\text { disease in the bone marrow (MRD-1) }\end{array}$ & NCT00172068 & $\begin{array}{l}\text { Zoledronic acid in } \\
\text { combination with } \\
\text { calcium/vitamin D }\end{array}$ & 96 & Terminated & 2 & $\begin{array}{l}\text { All patients treated became } \\
\text { DTC negative; untreated } \\
\text { patients } 12 \text { months after } \\
\text { diagnosis had significantly } \\
\text { shorter OS }\end{array}$ \\
\hline $\begin{array}{l}\text { Secondary adjuvant treatment for } \\
\text { patients with ITCs in bone marrow }\end{array}$ & NCT00248703 & Docetaxel & 1,028 & $\begin{array}{l}\text { Active, not } \\
\text { recruiting }\end{array}$ & 2 & $\begin{array}{l}79 \% \text { of patients became } \\
\text { DTC negative; enhanced } \\
\text { metastasis-free survival in } \\
\text { patients with DTC } \\
\text { elimination }\end{array}$ \\
\hline $\begin{array}{l}\text { Gedatolisib, Hydroxychloroquine or } \\
\text { the combination for prevention of } \\
\text { recurrent breast cancer (GLACIER) }\end{array}$ & NCT03400254 & $\begin{array}{l}\text { Hydroxychloroquine, } \\
\text { Gedatolisib, or } \\
\text { combination }\end{array}$ & 0 & Withdrawn & 3 & N/A \\
\hline $\begin{array}{l}\text { Phase II pilot trial of } \\
\text { Hydroxychloroquine, EVErolimus or } \\
\text { the combination for prevention of } \\
\text { recurrent breast cancer (CLEVER) }\end{array}$ & NCT03032406 & $\begin{array}{l}\text { Hydroxycholorquine, } \\
\text { everolimus, or } \\
\text { combination }\end{array}$ & 60 & Recruiting & 2 & $\mathrm{~N} / \mathrm{A}$ \\
\hline $\begin{array}{l}\text { Prolonged Tamoxifen compared with } \\
\text { shorter Tamoxifen in treating patients } \\
\text { who have breast cancer }\end{array}$ & NCT00003016 & Tamoxifen citrate & 20,000 & Terminated & N/A & $\mathrm{N} / \mathrm{A}$ \\
\hline $\begin{array}{l}\text { Pilot study of } 5 \text {-Azacitidine and } \\
\text { All-trans retinoic acid for prostate } \\
\text { cancer with PSA-only recurrence after } \\
\text { local treatment }\end{array}$ & NCT03572387 & $\begin{array}{l}\text { Combination of } \\
\text { 5-Azacitidine and } \\
\text { All-trans retinoic acid, or } \\
\text { no treatment }\end{array}$ & 20 & Recruiting & 2 & $\mathrm{~N} / \mathrm{A}$ \\
\hline $\begin{array}{l}\text { Phase II study comparing } \\
\text { chemotherapy in combination with } \\
\text { OGX-427 or placebo in patients with } \\
\text { bladder cancer }\end{array}$ & NCT01454089 & $\begin{array}{l}\text { Gemcitabine and } \\
\text { Cisplatin in combination } \\
\text { with OGX-427 }\end{array}$ & 183 & Completed & 2 & $\mathrm{~N} / \mathrm{A}$ \\
\hline $\begin{array}{l}\text { OGX-427 in castration resistant } \\
\text { prostate cancer patients }\end{array}$ & NCT01120470 & $\begin{array}{l}\text { OGX-427 and } \\
\text { prednisone in } \\
\text { combination }\end{array}$ & 74 & Completed & 2 & $\mathrm{~N} / \mathrm{A}$ \\
\hline $\begin{array}{l}\text { Safety and efficacy of ABT-510 in } \\
\text { subjects with advanced renal cell } \\
\text { carcinoma }\end{array}$ & NCT00073125 & $\begin{array}{l}\text { ABT- } \\
\text { 510/Thrombospondin-1 } \\
\text { mimetic }\end{array}$ & 103 & Completed & 2 & $\mathrm{~N} / \mathrm{A}$ \\
\hline $\begin{array}{l}\text { PROvenge treatment and early } \\
\text { cancer treatment }\end{array}$ & NCT00779402 & Sipuleucel-T & 176 & Completed & 3 & $\mathrm{~N} / \mathrm{A}$ \\
\hline $\begin{array}{l}\text { Sunitinib malate or Sorafenib tosylate } \\
\text { in treating patients with kidney cancer } \\
\text { that was removed by surgery }\end{array}$ & NCT00326898 & $\begin{array}{l}\text { Sunitinib malate or } \\
\text { sorafenib tosylate }\end{array}$ & 1,943 & Completed & 3 & $\begin{array}{l}\text { None of patients treated } \\
\text { showed survival benefit } \\
\text { relative to placebo }\end{array}$ \\
\hline
\end{tabular}

DC, dendritic cell; DFS, disease free survival; DTC, disseminating tumor cell; ITC, isolating tumor cell; N/A, not applicable; OS, overall survival.

cargo is relatively poor. This, coupled with a reduced capability to present antigen on MHC-I, renders dormant cells poorly immunogenic. Alternative strategies based on chimeric antigen receptor (CAR) T (304) and NK cells (305) can be developed to overcome these limitations. Second, the high intra- and interpatient heterogeneity of most tumors represents an additional challenge, that could be only addressed with cost-prohibitive personalized protocols. However, preclinical studies have shown 
the possibility of rapidly and easily reprogram circulating $\mathrm{T}$ cells in situ (306). Third, not all patients presenting DCCs in BM aspirates de facto develop metastases (137), and so it is of utmost importance to identify the additional parameters that characterize high-risk patients, thus avoiding the over-treatment of low-risk patients.

Lock-in strategies aim at artificially keeping cancer cells in a dormant state, thus preventing their outgrowth (138). To date, the Adjuvant Tamoxifen: Longer Against Shorter (ATLAS NCT00003016) is the most significant trial that has used a strategy specifically based on forcing dormancy maintenance (Table 2). In this clinical trial, ER positive breast cancer patients showed a significant reduction of disease recurrence and metastasis outgrowth, when the standard 5 year adjuvant tamoxifen administration was extended to 10 years $(307,308)$.

A plethora of signaling pathways previously identified as regulators of cancer cell quiescence in preclinical studies can be exploited as potential therapeutic targets. Specifically, two strategies can be conceived. The first strategy is based on the activation of dormancy-maintaining factors. Thus, the activation of the stress-activated protein kinase p38 was shown to preserve a state of protracted dormancy in different cancer types (99, 309). Similarly, in breast cancer models, induction of the morphoregulatory gene Homeobox (Hox)D10 reverted tumorigenic cells into a growth-arrested phenotype $(310,311)$. The same effects are ascribed to the multiple microenvironmental factors described above, which drive quiescence by triggering low-mitogenic and high-stress signaling. For instance, metastasis-incompetent primary tumors promoted the conversion of recruited myeloid cells from pro- to antimetastatic by forcing them to produce the antitumorigenic factor thrombospondin-1 (312). Moreover, stromal BMP7 triggered dormancy of prostate CSCs by activating p38, inducing the cell cycle inhibitor p21, and the metastasis suppressor NDRG1 (100), which is in line with the evidence that the inhibition of BMP4 reawakened dormant breast CSCs and favored lung colonization (150). Finally, the TGF- $\beta 2$ signaling was also involved in the maintenance and/or induction of a quiescent state for BM DCCs in a head and neck squamous cell carcinoma model (147).

A second strategy is based on the chronic silencing of reawakening pathways. Specifically, a blockade of uPAR affected the FN1-dependent mitogenic signaling, resulting in a lack of ERK1/2 activity and induction of dormancy in head and neck squamous cell carcinoma cells $(173,309)$. Similarly, suppression of MAPK/ERK axis and SFK signaling, favored quiescence in breast cancer models $(176,313)$. Also, the inhibition of the lysophosphatidic acid receptor 1 (LPAR1) induced dormancy of breast metastatic lesions by activating p38 signaling (74). The DNA methylation inhibitor 5-azacytidine interrupted the $\mathrm{G}_{0} \rightarrow \mathrm{G}_{1}$ switch in leukemia and breast cancer cells (314). In a subsequent study, the same authors showed that a combination of 5-azacytidine with bortezomib induces long-term dormancy multiple myeloma cells (315).

The advent of omics-based approaches disclosed single cell snapshots of molecular signatures associated with cancer dormancy $(106,316-318)$, some of which represent every promising target. Although theoretically highly attractive and clinically highly beneficial, the idea of keeping cancer (stem) cells asleep, may be difficult to translate into clinical settings. Some patients with a good prognosis and no more evidence of disease may be reluctant to continue therapy indefinitely. Moreover, long-term follow-ups and accumulating costs are additional challenges that need to be carefully considered. Interestingly, screening of the Prestwick Library, made up of Food and Drug Administration (FDA) approved drugs, led to the identification of the stimulant laxative drug bisacodyl as the sole agent specifically inhibiting quiescent, but not proliferating, glioblastoma stem-like cells (319). This opens the avenue to a third therapeutic strategy: the targeting of cancer (stem) cells while they are dormant. Intense basic and clinical research is developing, for example, target therapy with ABT-737, an inhibitor of anti-apoptotic BCL2 family members exerted a robust and preferential cytotoxic activity on quiescent lung CSCs (320). These findings opened the possibility to combine conventional chemotherapy with ABT-737 to kill otherwise resistant dormant CSCs, and thus prevent their relapse after reawakening (320).

We urge that more studies further explore dormancy regulation. These future studies will offer new possibilities for marker detection and metastatic prediction, opening a therapeutic window for prevention trials.

\section{CONCLUDING REMARKS}

This is an exciting moment for cancer research, with data bringing into sharp focus the complex factors and mechanisms that render the TME either metastasis-permissive or metastasissuppressive, but we still have a long way to go. The ability to anticipate whether, when, and how dormant DCCs are reactivated could help make cancer curative intent a reality. The striking analogies between dormant DCCs and dormant CSCs, along with their co-evolution with the surrounding microenvironment, may provide the ground for developing therapies that consider dormancy as a whole process. This opportunity to rethink therapeutic strategies could be the way to eradicate and/or prevent lethal metastatic recurrence and would surely benefit from the possibility of monitoring dormancy over time through rigorous, non-invasive, and preferably lowcost approaches.

\section{AUTHOR CONTRIBUTIONS}

AS and RDM conceived the paper. AS wrote the first version of the manuscript and designed the figures with the help of MM, under the supervision of RDM. AS, MM, and CG prepared the tables, under the supervision of RDM. IV provided critical input to the preparation of the paper. All authors approved the final version of the article. 


\section{FUNDING}

AS was supported by the Associazione Italiana per la Ricerca sul Cancro (AIRC, Start-Up 2016 \#18418) and Ministero Italiano della Salute (RF_GR-2013-02357273). IV was supported by the

\section{REFERENCES}

1. Aguirre-Ghiso JA. Models, mechanisms and clinical evidence for cancer dormancy. Nat Rev Cancer. (2007) 7:834-46. doi: 10.1038/nrc2256

2. Hadfield G. The dormant cancer cell. Br Med J. (1954) 2:607-10. doi: $10.1136 /$ bmj.2.4888.607

3. Linde N, Fluegen G, Aguirre-Ghiso JA. The relationship between dormant cancer cells and their microenvironment. Adv Cancer Res. (2016) 132:45-71. doi: 10.1016/bs.acr.2016.07.002

4. Manjili MH. Tumor dormancy and relapse: from a natural byproduct of evolution to a disease state. Cancer Res. (2017) 77:2564-9. doi: 10.1158/0008-5472.CAN-17-0068

5. Vitale I, Sistigu A, Manic G, Rudqvist NP, Trajanoski Z, Galluzzi L. Mutational and antigenic landscape in tumor progression and cancer immunotherapy. Trends Cell Biol. (2019) 29:396-416. doi: 10.1016/j.tcb.2019.01.003

6. Kleffel S, Schatton T. Tumor dormancy and cancer stem cells: two sides of the same coin? Adv Exp Med Biol. (2013) 734:145-79. doi: 10.1007/978-1-4614-1445-2_8

7. Talukdar S, Bhoopathi P, Emdad L, Das S, Sarkar D, Fisher PB. Dormancy and cancer stem cells: an enigma for cancer therapeutic targeting. Adv Cancer Res. (2019) 141:43-84. doi: 10.1016/bs.acr.2018.12.002

8. Maccalli C, De Maria R. Cancer stem cells: perspectives for therapeutic targeting. Cancer Immunol Immunother. (2015) 64:91-7. doi: $10.1007 / \mathrm{s} 00262-014-1592-1$

9. Batlle E, Clevers H. Cancer stem cells revisited. Nat Med. (2017) 23:1124-34. doi: $10.1038 / \mathrm{nm} .4409$

10. Fiori ME, Villanova L, De Maria R. Cancer stem cells: at the forefront of personalized medicine and immunotherapy. Curr Opin Pharmacol. (2017) 35:1-11. doi: 10.1016/j.coph.2017.04.006

11. Turdo A, Veschi V, Gaggianesi M, Chinnici A, Bianca P, Todaro M, et al. Meeting the challenge of targeting cancer stem cells. Front Cell Dev Biol. (2019) 7:16. doi: 10.3389/fcell.2019.00016

12. Holmgren L, O'reilly MS, Folkman J. Dormancy of micrometastases: balanced proliferation and apoptosis in the presence of angiogenesis suppression. Nat Med. (1995) 1:149-53. doi: 10.1038/nm0295-149

13. Koebel CM, Vermi W, Swann JB, Zerafa N, Rodig SJ, Old LJ, et al. Adaptive immunity maintains occult cancer in an equilibrium state. Nature. (2007) 450:903-7. doi: 10.1038/nature06309

14. Goddard ET, Bozic I, Riddell SR, Ghajar CM. Dormant tumour cells, their niches and the influence of immunity. Nat Cell Biol. (2018) 20:1240-9. doi: 10.1038/s41556-018-0214-0

15. Galluzzi L, Vitale I. Oncogene-induced senescence and tumour control in complex biological systems. Cell Death Differ. (2018) 25:1005-6. doi: 10.1038/s41418-018-0102-y

16. Chakradeo S, Elmore LW, Gewirtz DA. Is senescence reversible? Curr Drug Targets. (2016) 17:460-6. doi: 10.2174/1389450116666150825113500

17. Lambert AW, Pattabiraman DR, Weinberg RA. Emerging biological principles of metastasis. Cell. (2017) 168:670-91. doi: 10.1016/j.cell.2016.11.037

18. Dillekas H, Rogers MS, Straume O. Are $90 \%$ of deaths from cancer caused by metastases? Cancer Med. (2019) 8:5574-6. doi: 10.1002/cam4.2474

19. Valastyan S, Weinberg RA. Tumor metastasis: molecular insights and evolving paradigms. Cell. (2011) 147:275-92. doi: 10.1016/j.cell.2011.09.024

20. Fidler IJ. The pathogenesis of cancer metastasis: the 'seed and soil' hypothesis revisited. Nat Rev Cancer. (2003) 3:453-8. doi: 10.1038/nrc1098

21. Gupta GP, Massague J. Cancer metastasis: building a framework. Cell. (2006) 127:679-95. doi: 10.1016/j.cell.2006.11.001

22. Welch DR, Hurst DR. Defining the hallmarks of metastasis. Cancer Res. (2019) 79:3011-27. doi: 10.1158/0008-5472.CAN-19-0458
Associazione Italiana per la Ricerca sul Cancro (AIRC, IG \#20417) and a startup grant from the Italian Institute for Genomic Medicine (Candiolo, Turin, Italy) and Compagnia di San Paolo (Torino, Italy). RDM was supported by Associazione Italiana per la Ricerca sul Cancro (AIRC, 5x1000 \#9979).

23. Chaffer CL, Weinberg RA. A perspective on cancer cell metastasis. Science. (2011) 331:1559-64. doi: 10.1126/science.1203543

24. Massague J, Obenauf AC. Metastatic colonization by circulating tumour cells. Nature. (2016) 529:298-306. doi: 10.1038/nature17038

25. Giancotti FG. Mechanisms governing metastatic dormancy and reactivation. Cell. (2013) 155:750-64. doi: 10.1016/j.cell.2013.10.029

26. Luzzi KJ, Macdonald IC, Schmidt EE, Kerkvliet N, Morris VL, Chambers AF, et al. Multistep nature of metastatic inefficiency: dormancy of solitary cells after successful extravasation and limited survival of early micrometastases. Am J Pathol. (1998) 153:865-73. doi: 10.1016/S0002-9440(10)65628-3

27. Yachida S, Jones S, Bozic I, Antal T, Leary R, Fu B, et al. Distant metastasis occurs late during the genetic evolution of pancreatic cancer. Nature. (2010) 467:1114-7. doi: 10.1038/nature09515

28. Bernards R, Weinberg RA. A progression puzzle. Nature. (2002) 418:823. doi: $10.1038 / 418823 a$

29. Ince TA, Richardson AL, Bell GW, Saitoh M, Godar S, Karnoub AE, et al. Transformation of different human breast epithelial cell types leads to distinct tumor phenotypes. Cancer Cell. (2007) 12:160-70. doi: 10.1016/j.ccr.2007.06.013

30. Bhowmick NA, Neilson EG, Moses HL. Stromal fibroblasts in cancer initiation and progression. Nature. (2004) 432:332-7. doi: 10.1038/nature03096

31. Ding L, Ellis MJ, Li S, Larson DE, Chen K, Wallis JW, et al. Genome remodelling in a basal-like breast cancer metastasis and xenograft. Nature. (2010) 464:999-1005. doi: 10.1038/nature08989

32. Wu X, Northcott PA, Dubuc A, Dupuy AJ, Shih DJ, Witt H, et al. Clonal selection drives genetic divergence of metastatic medulloblastoma. Nature. (2012) 482:529-33. doi: 10.1038/nature10825

33. Husemann Y, Geigl JB, Schubert F, Musiani P, Meyer M, Burghart E, et al. Systemic spread is an early step in breast cancer. Cancer Cell. (2008) 13:5868. doi: 10.1016/j.ccr.2007.12.003

34. Podsypanina K, Du YC, Jechlinger M, Beverly LJ, Hambardzumyan D, Varmus H. Seeding and propagation of untransformed mouse mammary cells in the lung. Science. (2008) 321:1841-4. doi: 10.1126/science.1161621

35. Klein CA. Parallel progression of primary tumours and metastases. Nat Rev Cancer. (2009) 9:302-12. doi: 10.1038/nrc2627

36. Rhim AD, Mirek ET, Aiello NM, Maitra A, Bailey JM, Mcallister F, et al. EMT and dissemination precede pancreatic tumor formation. Cell. (2012) 148:349-61. doi: 10.1016/j.cell.2011.11.025

37. Harper KL, Sosa MS, Entenberg D, Hosseini H, Cheung JF, Nobre R, et al. Mechanism of early dissemination and metastasis in $\mathrm{Her}^{+}$mammary cancer. Nature. (2016) 540:588-92. doi: 10.1038/nature20609

38. Hosseini H, Obradovic MMS, Hoffmann M, Harper KL, Sosa MS, WernerKlein M, et al. Early dissemination seeds metastasis in breast cancer. Nature. (2016) 540:552-8. doi: 10.1038/nature20785

39. Campbell PJ, Yachida S, Mudie LJ, Stephens PJ, Pleasance ED, Stebbings LA, et al. The patterns and dynamics of genomic instability in metastatic pancreatic cancer. Nature. (2010) 467:1109-13. doi: 10.1038/nature09460

40. Gerlinger M, Rowan AJ, Horswell S, Math M, Larkin J, Endesfelder D, et al. Intratumor heterogeneity and branched evolution revealed by multiregion sequencing. N Engl J Med. (2012) 366:883-92. doi: 10.1056/NEJMoa1113205

41. Kim MY, Oskarsson T, Acharyya S, Nguyen DX, Zhang XH, Norton L, et al. Tumor self-seeding by circulating cancer cells. Cell. (2009) 139:1315-26. doi: 10.1016/j.cell.2009.11.025

42. Kurppa KJ, Liu Y, To C, Zhang T, Fan M, Vajdi A, et al. Treatment-induced tumor dormancy through YAP-mediated transcriptional reprogramming of the apoptotic pathway. Cancer Cell. (2020) 37:104-22.e112. doi: 10.1016/j.ccell.2019.12.006

43. Almog N. Molecular mechanisms underlying tumor dormancy. Cancer Lett. (2010) 294:139-46. doi: 10.1016/j.canlet.2010.03.004 
44. Korah R, Boots M, Wieder R. Integrin alpha5beta1 promotes survival of growtharrested breast cancer cells: an in vitro paradigm for breast cancer dormancy in bone marrow. Cancer Res. (2004) 64:4514-22. doi: 10.1158/0008-5472.CAN-03-3853

45. Tivari S, Korah R, Lindy M, Wieder R. An in vitro dormancy model of estrogensensitive breast cancer in the bone marrow: a tool for molecular mechanism studies and hypothesis generation. J Vis Exp. (2015) e52672. doi: $10.3791 / 52672$

46. Barkan D, El Touny LH, Michalowski AM, Smith JA, Chu I, Davis AS, et al. Metastatic growth from dormant cells induced by a colI-enriched fibrotic environment. Cancer Res. (2010) 70:5706-16. doi: 10.1158/0008-5472.CAN-09-2356

47. Barkan D, Green JE. An in vitro system to study tumor dormancy and the switch to metastatic growth. J Vis Exp. (2011) 2614. doi: 10.3791/2914

48. Ghajar CM, Peinado H, Mori H, Matei IR, Evason KJ, Brazier H, et al. The perivascular niche regulates breast tumour dormancy. Nat Cell Biol. (2013) 15:807-17. doi: 10.1038/ncb2767

49. Marlow R, Honeth G, Lombardi S, Cariati M, Hessey S, Pipili A, et al. A novel model of dormancy for bone metastatic breast cancer cells. Cancer Res. (2013) 73:6886-99. doi: 10.1158/0008-5472.CAN-13-0991

50. Fang JY, Tan SJ, Wu YC, Yang Z, Hoang BX, Han B. From competency to dormancy: a 3D model to study cancer cells and drug responsiveness. J Transl Med. (2016) 14:38. doi: 10.1186/s12967-016-0798-8

51. Pavan Grandhi TS, Potta T, Nitiyanandan R, Deshpande I, Rege K. Chemomechanically engineered 3D organotypic platforms of bladder cancer dormancy and reactivation. Biomaterials. (2017) 142:171-85. doi: 10.1016/j.biomaterials.2017.07.008

52. Lee HR, Leslie F, Azarin SM. A facile in vitro platform to study cancer cell dormancy under hypoxic microenvironments using CoCl2. J Biol Eng. (2018) 12:12. doi: 10.1186/s13036-018-0106-7

53. Jia Q, Yang F, Huang W, Zhang Y, Bao B, Li K, et al. Low levels of Sox2 are required for melanoma tumor-repopulating cell dormancy. Theranostics. (2019) 9:424-35. doi: 10.7150/thno.29698

54. Narkhede AA, Crenshaw JH, Crossman DK, Shevde LA, Rao SS. An in vitro hyaluronic acid hydrogel based platform to model dormancy in brain metastatic breast cancer cells. Acta Biomater. (2020) 107:65-77. doi: 10.1016/j.actbio.2020.02.039

55. Clark AM, Wheeler SE, Young CL, Stockdale L, Shepard Neiman J, Zhao $\mathrm{W}$, et al. A liver microphysiological system of tumor cell dormancy and inflammatory responsiveness is affected by scaffold properties. Lab Chip. (2016) 17:156-68. doi: 10.1039/C6LC01171C

56. Wheeler SE, Clark AM, Taylor DP, Young CL, Pillai VC, Stolz DB, et al. Spontaneous dormancy of metastatic breast cancer cells in an all human liver microphysiologic system. Br J Cancer. (2014) 111:2342-50. doi: 10.1038/bjc. 2014.533

57. Khazali AS, Clark AM, Wells A. Inflammatory cytokine IL-8/CXCL8 promotes tumour escape from hepatocyte-induced dormancy. Br J Cancer. (2018) 118:566-76. doi: 10.1038/bjc.2017.414

58. Clark AM, Kumar MP, Wheeler SE, Young CL, Venkataramanan R, Stolz DB, et al. A model of dormant-emergent metastatic breast cancer progression enabling exploration of biomarker signatures. Mol Cell Proteomics. (2018) 17:619-30. doi: 10.1074/mcp.RA117.000370

59. Hassell BA, Goyal G, Lee E, Sontheimer-Phelps A, Levy O, Chen CS, et al. Human organ chip models recapitulate orthotopic lung cancer growth, therapeutic responses, and tumor dormancy in vitro. Cell Rep. (2017) 21:50816. doi: 10.1016/j.celrep.2017.09.043

60. Sosnoski DM, Norgard RJ, Grove CD, Foster SJ, Mastro AM. Dormancy and growth of metastatic breast cancer cells in a bone-like microenvironment. Clin Exp Metastasis. (2015) 32:335-44. doi: 10.1007/s10585-015-9710-9

61. Vitetta ES, Tucker TF, Racila E, Huang YW, Marches R, Lane N, et al. Tumor dormancy and cell signaling. V. Regrowth of the BCL1 tumor after dormancy is established. Blood. (1997) 89:4425-36. doi: 10.1182/blood.V89.12.4425

62. Saudemont A, Quesnel B. In a model of tumor dormancy, longterm persistent leukemic cells have increased B7-H1 and B7.1 expression and resist CTL-mediated lysis. Blood. (2004) 104:2124-33. doi: 10.1182/blood-2004-01-0064

63. Naumov GN, Macdonald IC, Weinmeister PM, Kerkvliet N, Nadkarni $\mathrm{KV}$, Wilson SM, et al. Persistence of solitary mammary carcinoma cells in a secondary site: a possible contributor to dormancy. Cancer Res. (2002) 62:2162-8.

64. Box GM, Eccles SA. Simple experimental and spontaneous metastasis assays in mice. Methods Mol Biol. (2011) 769:311-29. doi: 10.1007/978-1-61779-207-6_21

65. Montagner M, Bhome R, Hooper S, Chakravarty P, Qin X, Sufi J, et al. Crosstalk with lung epithelial cells regulates Sfrp2-mediated latency in breast cancer dissemination. Nat Cell Biol. (2020) 22:289-96. doi: 10.1038/s41556-020-0474-3

66. Wang H, Yu C, Gao X, Welte T, Muscarella AM, Tian L, et al. The osteogenic niche promotes early-stage bone colonization of disseminated breast cancer cells. Cancer Cell. (2015) 27:193-210. doi: 10.1016/j.ccell.2014.11.017

67. Izraely S, Sagi-Assif O, Klein A, Meshel T, Tsarfaty G, Pasmanik-Chor $\mathrm{M}$, et al. The metastatic microenvironment: brain-residing melanoma metastasis and dormant micrometastasis. Int J Cancer. (2012) 131:1071-82. doi: 10.1002/ijc. 27324

68. Lawson MA, Mcdonald MM, Kovacic N, Hua Khoo W, Terry RL, Down J, et al. Osteoclasts control reactivation of dormant myeloma cells by remodelling the endosteal niche. Nat Commun. (2015) 6:8983. doi: $10.1038 /$ ncomms 9983

69. Sakamoto $S$, Inoue $H$, Ohba $S$, Kohda $Y$, Usami I, Masuda $T$, et al. New metastatic model of human small-cell lung cancer by orthotopic transplantation in mice. Cancer Sci. (2015) 106:367-74. doi: $10.1111 /$ cas.12624

70. Gao D, Nolan DJ, Mellick AS, Bambino K, Mcdonnell K, Mittal V. Endothelial progenitor cells control the angiogenic switch in mouse lung metastasis. Science. (2008) 319:195-8. doi: 10.1126/science.1150224

71. Ying H, Kimmelman AC, Lyssiotis CA, Hua S, Chu GC, FletcherSananikone E, et al. Oncogenic Kras maintains pancreatic tumors through regulation of anabolic glucose metabolism. Cell. (2012) 149:656-70. doi: 10.1016/j.cell.2012.01.058

72. Lin WC, Rajbhandari N, Wagner KU. Cancer cell dormancy in novel mouse models for reversible pancreatic cancer: a lingering challenge in the development of targeted therapies. Cancer Res. (2014) 74:2138-43. doi: 10.1158/0008-5472.CAN-13-3437

73. Flores-Guzman F, Utikal J, Umansky V. Dormant tumor cells interact with memory CD8 ${ }^{+} \mathrm{T}$ cells in RET transgenic mouse melanoma model. Cancer Lett. (2020) 474:74-81. doi: 10.1016/j.canlet.2020.01.016

74. Marshall JC, Collins JW, Nakayama J, Horak CE, Liewehr DJ, Steinberg $\mathrm{SM}$, et al. Effect of inhibition of the lysophosphatidic acid receptor 1 on metastasis and metastatic dormancy in breast cancer. J Natl Cancer Inst. (2012) 104:1306-19. doi: 10.1093/jnci/djs319

75. Krall JA, Reinhardt F, Mercury OA, Pattabiraman DR, Brooks MW, Dougan $\mathrm{M}$, et al. The systemic response to surgery triggers the outgrowth of distant immune-controlled tumors in mouse models of dormancy. Sci Transl Med. (2018) 10:eaan3464. doi: 10.1126/scitranslmed.aan3464

76. Giuliano M, Herrera S, Christiny P, Shaw C, Creighton CJ, Mitchell T, et al. Circulating and disseminated tumor cells from breast cancer patient-derived xenograft-bearing mice as a novel model to study metastasis. Breast Cancer Res. (2015) 17:3. doi: 10.1186/s13058-014-0508-5

77. Lawson DA, Bhakta NR, Kessenbrock K, Prummel KD, Yu Y, Takai $\mathrm{K}$, et al. Single-cell analysis reveals a stem-cell program in human metastatic breast cancer cells. Nature. (2015) 526:131-5. doi: 10.1038/nature 15260

78. Williams ES, Rodriguez-Bravo V, Chippada-Venkata U, De Ia Iglesia-Vicente J, Gong Y, Galsky M, et al. Generation of prostate cancer patient derived xenograft models from circulating tumor cells. J Vis Exp. (2015) 53182. doi: $10.3791 / 53182$

79. Page K, Uhr JW. Mathematical models of cancer dormancy. Leuk Lymph. (2005) 46:313-27. doi: 10.1080/10428190400011625

80. Wilkie KP. A review of mathematical models of cancer-immune interactions in the context of tumor dormancy. Adv Exp Med Biol. (2013) 734:201-34. doi: 10.1007/978-1-4614-1445-2_10

81. Wilkie KP, Hahnfeldt P. Mathematical models of immune-induced cancer dormancy and the emergence of immune evasion. Interface Focus. (2013) 3:20130010. doi: 10.1098/rsfs.2013.0010

82. Chen JC, Alvarez MJ, Talos F, Dhruv H, Rieckhof GE, Iyer A, et al. Identification of causal genetic drivers of human disease through 
systems-level analysis of regulatory networks. Cell. (2014) 159:402-14. doi: 10.1016/j.cell.2014.09.021

83. Poleszczuk J, Hahnfeldt P, Enderling H. Evolution and phenotypic selection of cancer stem cells. PLoS Comput Biol. (2015) 11:e1004025. doi: 10.1371/journal.pcbi.1004025

84. Ahmad FK, Deris S, Othman NH. The inference of breast cancer metastasis through gene regulatory networks. J Biomed Inform. (2012) 45:350-62. doi: 10.1016/j.jbi.2011.11.015

85. Liang Y, Wu H, Lei R, Chong RA, Wei Y, Lu X, et al. Transcriptional network analysis identifies $\mathrm{BACH1}$ as a master regulator of breast cancer bone metastasis. J Biol Chem. (2012) 287:33533-44. doi: 10.1074/jbc.M112.392332

86. Suhail Y, Cain MP, Vanaja K, Kurywchak PA, Levchenko A, Kalluri R, et al. Systems biology of cancer metastasis. Cell Syst. (2019) 9:109-27. doi: 10.1016/j.cels.2019.07.003

87. Kelly SE, Di Benedetto A, Greco A, Howard CM, Sollars VE, Primerano $\mathrm{DA}$, et al. Rapid selection and proliferation of CD133+ cells from cancer cell lines: chemotherapeutic implications. PLOS ONE. (2010) 5:e10035. doi: 10.1371/journal.pone. 0010035

88. Mathis SE, Alberico A, Nande R, Neto W, Lawrence L, Mccallister $\mathrm{DR}$, et al. Chemo-predictive assay for targeting cancer stem-like cells in patients affected by brain tumors. PLoS ONE. (2014) 9:e105710. doi: 10.1371/journal.pone.0105710

89. Howard CM, Valluri J, Alberico A, Julien T, Mazagri R, Marsh $\mathrm{R}$, et al. Analysis of chemopredictive assay for targeting cancer stem cells in glioblastoma patients. Transl Oncol. (2017) 10:241-54. doi: 10.1016/j.tranon.2017.01.008

90. Pradhan S, Sperduto JL, Farino CJ, Slater JH. Engineered in vitro models of tumor dormancy and reactivation. J Biol Eng. (2018) 12:37. doi: 10.1186/s13036-018-0120-9

91. Ranjan T, Howard CM, Yu A, Xu L, Aziz K, Jho D, et al. Cancer stem cell chemotherapeutics assay for prospective treatment of recurrent glioblastoma and progressive anaplastic glioma: a single-institution case series. Transl Oncol. (2020) 13:100755. doi: 10.1016/j.tranon.2020.100755

92. Kapalczynska M, Kolenda T, Przybyla W, Zajaczkowska M, Teresiak A, Filas $\mathrm{V}$, et al. 2D and 3D cell cultures - a comparison of different types of cancer cell cultures. Arch Med Sci. (2018) 14:910-9. doi: 10.5114/aoms.2016.63743

93. Demicheli R, Retsky MW, Hrushesky WJ, Baum M. Tumor dormancy and surgery-driven interruption of dormancy in breast cancer: learning from failures. Nat Clin Pract Oncol. (2007) 4:699-710. doi: 10.1038/ncponc0999

94. Dean M, Fojo T, Bates S. Tumour stem cells and drug resistance. Nat Rev Cancer. (2005) 5:275-84. doi: 10.1038/nrc1590

95. Mani SA, Guo W, Liao MJ, Eaton EN, Ayyanan A, Zhou AY, et al. The epithelial-mesenchymal transition generates cells with properties of stem cells. Cell. (2008) 133:704-15. doi: 10.1016/j.cell.2008.03.027

96. Gupta PB, Fillmore CM, Jiang G, Shapira SD, Tao K, Kuperwasser C, et al. Stochastic state transitions give rise to phenotypic equilibrium in populations of cancer cells. Cell. (2011) 146:633-44. doi: 10.1016/j.cell.2011.07.026

97. Plaks V, Kong N, Werb Z. The cancer stem cell niche: how essential is the niche in regulating stemness of tumor cells? Cell Stem Cell. (2015) 16:225-38. doi: 10.1016/j.stem.2015.02.015

98. Oskarsson T, Batlle E, Massague J. Metastatic stem cells: sources, niches, and vital pathways. Cell Stem Cell. (2014) 14:306-21. doi: 10.1016/j.stem.2014.02.002

99. Aguirre-Ghiso JA, Estrada Y, Liu D, Ossowski L. ERK(MAPK) activity as a determinant of tumor growth and dormancy; regulation by p38(SAPK). Cancer Res. (2003) 63:1684-95. doi: 10.1016/j.urolonc.2003.12.012

100. Kobayashi A, Okuda H, Xing F, Pandey PR, Watabe M, Hirota S, et al. Bone morphogenetic protein 7 in dormancy and metastasis of prostate cancer stem-like cells in bone. J Exp Med. (2011) 208:2641-55. doi: 10.1084 /jem.20110840

101. Schewe DM, Aguirre-Ghiso JA. ATF6alpha-Rheb-mTOR signaling promotes survival of dormant tumor cells in vivo. Proc Natl Acad Sci USA. (2008) 105:10519-24. doi: 10.1073/pnas.0800939105

102. Gaur P, Sceusi EL, Samuel S, Xia L, Fan F, Zhou Y, et al. Identification of cancer stem cells in human gastrointestinal carcinoid and neuroendocrine tumors. Gastroenterology. (2011) 141:1728-37. doi: 10.1053/j.gastro.2011.07.037
103. Shiozawa Y, Berry JE, Eber MR, Jung Y, Yumoto K, Cackowski FC, et al. The marrow niche controls the cancer stem cell phenotype of disseminated prostate cancer. Oncotarget. (2016) 7:41217-32. doi: 10.18632/oncotarget.9251

104. Pannuti A, Foreman K, Rizzo P, Osipo C, Golde T, Osborne B, et al. Targeting notch to target cancer stem cells. Clin Cancer Res. (2010) 16:3141-52. doi: 10.1158/1078-0432.CCR-09-2823

105. Abel EV, Kim EJ, Wu J, Hynes M, Bednar F, Proctor E, et al. The Notch pathway is important in maintaining the cancer stem cell population in pancreatic cancer. PLoS ONE. (2014) 9:e91983. doi: 10.1371/journal.pone.0091983

106. Kim JH, Park SY, Jun Y, Kim JY, Nam JS. Roles of Wnt target genes in the journey of cancer stem cells. Int J Mol Sci. (2017) 18:1604. doi: $10.3390 / \mathrm{ijms} 18081604$

107. Nguyen DX, Chiang AC, Zhang XH, Kim JY, Kris MG, Ladanyi $M$, et al. WNT/TCF signaling through LEF1 and HOXB9 mediates lung adenocarcinoma metastasis. Cell. (2009) 138:51-62. doi: 10.1016/j.cell.2009.04.030

108. Abravanel DL, Belka GK, Pan TC, Pant DK, Collins MA, Sterner CJ, et al. Notch promotes recurrence of dormant tumor cells following HER2/neutargeted therapy. J Clin Invest. (2015) 125:2484-96. doi: 10.1172/JCI74883

109. Shachaf CM, Kopelman AM, Arvanitis C, Karlsson A, Beer S, Mandl $S$, et al. MYC inactivation uncovers pluripotent differentiation and tumour dormancy in hepatocellular cancer. Nature. (2004) 431:1112-7. doi: 10.1038/nature03043

110. Wu CH, Van Riggelen J, Yetil A, Fan AC, Bachireddy P, Felsher DW. Cellular senescence is an important mechanism of tumor regression upon c-Myc inactivation. Proc Natl Acad Sci USA. (2007) 104:13028-33. doi: 10.1073/pnas.0701953104

111. Civenni G, Malek A, Albino D, Garcia-Escudero R, Napoli S, Di Marco $S$, et al. RNAi-mediated silencing of Myc transcription inhibits stem-like cell maintenance and tumorigenicity in prostate cancer. Cancer Res. (2013) 73:6816-27. doi: 10.1158/0008-5472.CAN-13-0615

112. Yang A, Qin S, Schulte BA, Ethier SP, Tew KD, Wang GY. MYC inhibition depletes cancer stem-like cells in triple-negative breast cancer. Cancer Res. (2017) 77:66416650. doi: 10.1158/0008-5472.CAN-16-3452

113. Joensuu K, Hagstrom J, Leidenius M, Haglund C, Andersson LC, Sariola H, et al. Bmi-1, c-myc, and snail expression in primary breast cancers and their metastases-elevated Bmi-1 expression in late breast cancer relapses. Virchows Arch. (2011) 459:31-9. doi: 10.1007/s00428-011-1096-8

114. Liu S, Dontu G, Mantle ID, Patel S, Ahn NS, Jackson KW, et al. Hedgehog signaling and Bmi-1 regulate self-renewal of normal and malignant human mammary stem cells. Cancer Res. (2006) 66:6063-71. doi: 10.1158/0008-5472.CAN-06-0054

115. Johnson RW, Finger EC, Olcina MM, Vilalta M, Aguilera T, Miao Y, et al. Erratum: induction of LIFR confers a dormancy phenotype in breast cancer cells disseminated to the bone marrow. Nat Cell Biol. (2016) 18:1260. doi: $10.1038 / \mathrm{ncb} 3433$

116. Filomeni G, De Zio D, Cecconi F. Oxidative stress and autophagy: the clash between damage and metabolic needs. Cell Death Differ. (2015) 22:377-88. doi: 10.1038/cdd.2014.150

117. Sosa MS, Bragado P, Debnath J, Aguirre-Ghiso JA. Regulation of tumor cell dormancy by tissue microenvironments and autophagy. Adv Exp Med Biol. (2013) 734:73-89. doi: 10.1007/978-1-4614-1445-2_5

118. Vitale I, Manic G, Dandrea V, De Maria R. Role of autophagy in the maintenance and function of cancer stem cells. Int J Dev Biol. (2015) 59:95-108. doi: 10.1387/ijdb.150082iv

119. Vera-Ramirez L, Vodnala SK, Nini R, Hunter KW, Green JE. Autophagy promotes the survival of dormant breast cancer cells and metastatic tumour recurrence. Nat Commun. (2018) 9:1944. doi: 10.1038/s41467-018-04070-6

120. Nazio F, Bordi M, Cianfanelli V, Locatelli F, Cecconi F. Autophagy and cancer stem cells: molecular mechanisms and therapeutic applications. Cell Death Differ. (2019) 26:690702. doi: 10.1038/s41418-019-0292-y

121. Marcucci F, Stassi G, De Maria R. Epithelial-mesenchymal transition: a new target in anticancer drug discovery. Nat Rev Drug Discov. (2016) 15:311-25. doi: $10.1038 / \mathrm{nrd} .2015 .13$ 
122. Wei SC, Yang J. Forcing through tumor metastasis: the interplay between tissue rigidity and epithelial-mesenchymal transition. Trends Cell Biol. (2016) 26:111-20. doi: 10.1016/j.tcb.2015.09.009

123. Weidenfeld K, Schif-Zuck S, Abu-Tayeh H, Kang K, Kessler O, Weissmann $\mathrm{M}$, et al. Dormant tumor cells expressing LOXL2 acquire a stem-like phenotype mediating their transition to proliferative growth. Oncotarget. (2016) 7:71362-77. doi: 10.18632/oncotarget.12109

124. Chaffer CL, Marjanovic ND, Lee T, Bell G, Kleer CG, Reinhardt F, et al. Poised chromatin at the ZEB1 promoter enables breast cancer cell plasticity and enhances tumorigenicity. Cell. (2013) 154:61-74. doi: 10.1016/j.cell.2013.06.005

125. De Cock JM, Shibue T, Dongre A, Keckesova Z, Reinhardt F, Weinberg RA. Inflammation triggers Zeb1-dependent escape from tumor latency. Cancer Res. (2016) 76:6778-84. doi: 10.1158/0008-5472.CAN-16-0608

126. Francescangeli F, Contavalli P, De Angelis ML, Careccia S, Signore M, Haas $\mathrm{TL}$, et al. A pre-existing population of $\mathrm{ZEB}^{+}{ }^{+}$quiescent cells with stemness and mesenchymal features dictate chemoresistance in colorectal cancer. $J$ Exp Clin Cancer Res. (2020) 39:2. doi: 10.1186/s13046-019-1505-4

127. Hen O, Barkan D. Dormant disseminated tumor cells and cancer stem/progenitor-like cells: similarities and opportunities. Semin Cancer Biol. (2020) 60:157-65. doi: 10.1016/j.semcancer.2019.09.002

128. Francescangeli F, Patrizii M, Signore M, Federici G, Di Franco S, Pagliuca A, et al. Proliferation state and polo-like kinase1 dependence of tumorigenic colon cancer cells. Stem Cells. (2012) 30:1819-30. doi: 10.1002/stem.1163

129. Crea F, Nur Saidy NR, Collins CC, Wang Y. The epigenetic/noncoding origin of tumor dormancy. Trends Mol Med. (2015) 21:206-11. doi: 10.1016/j.molmed.2015.02.005

130. Vitale I, Manic G, De Maria R, Kroemer G, Galluzzi L. DNA damage in stem cells. Mol Cell. (2017) 66:306-19. doi: 10.1016/j.molcel.2017.04.006

131. Sosa MS, Bragado P, Aguirre-Ghiso JA. Mechanisms of disseminated cancer cell dormancy: an awakening field. Nat Rev Cancer. (2014) 14:611-22. doi: $10.1038 / \mathrm{nrc} 3793$

132. Yeh AC, Ramaswamy S. Mechanisms of cancer cell dormancyanother hallmark of cancer? Cancer Res. (2015) 75:5014-22. doi: 10.1158/0008-5472.CAN-15-1370

133. Gao XL, Zhang M, Tang YL, Liang XH. Cancer cell dormancy: mechanisms and implications of cancer recurrence and metastasis. Onco Targets Ther. (2017) 10:5219-28. doi: 10.2147/OTT.S140854

134. Jahanban-Esfahlan R, Seidi K, Manjili MH, Jahanban-Esfahlan A, Javaheri T, Zare P. Tumor cell dormancy: threat or opportunity in the fight against cancer. Cancers. (2019) 11:1207. doi: 10.3390/cancers11081207

135. Peinado H, Zhang H, Matei IR, Costa-Silva B, Hoshino A, Rodrigues G, et al. Pre-metastatic niches: organ-specific homes for metastases. Nat Rev Cancer. (2017) 17:302-17. doi: 10.1038/nrc.2017.6

136. Celia-Terrassa T, Kang Y. Metastatic niche functions and therapeutic opportunities. Nat Cell Biol. (2018) 20:868-77. doi: 10.1038/s41556-018-0145-9

137. Braun S, Vogl FD, Naume B, Janni W, Osborne MP, Coombes RC, et al. A pooled analysis of bone marrow micrometastasis in breast cancer. $N$ Engl J Med. (2005) 353:793-802. doi: 10.1056/NEJMoa050434

138. Ghajar CM. Metastasis prevention by targeting the dormant niche. Nat Rev Cancer. (2015) 15:238-47. doi: 10.1038/nrc3910

139. Eaves CJ. Hematopoietic stem cells: concepts, definitions, and the new reality. Blood. (2015) 125:2605-13. doi: 10.1182/blood-2014-12-570200

140. Capulli M, Hristova D, Valbret Z, Carys K, Arjan R, Maurizi A, et al. Notch2 pathway mediates breast cancer cellular dormancy and mobilisation in bone and contributes to haematopoietic stem cell mimicry. Br J Cancer. (2019) 121:157-71. doi: 10.1038/s41416-019-0501-y

141. Kahn M. Can we safely target the WNT pathway? Nat Rev Drug Discov. (2014) 13:513-32.

142. Buczacki SJA, Popova S, Biggs E, Koukorava C, Buzzelli J, Vermeulen L, et al. Itraconazole targets cell cycle heterogeneity in colorectal cancer. J Exp Med. (2018) 215:1891-912. doi: 10.1084/jem.20171385

143. Ren D, Dai Y, Yang Q, Zhang X, Guo W, Ye L, et al. Wnt5a induces and maintains prostate cancer cells dormancy in bone. J Exp Med. (2019) 216:428-49. doi: 10.1084/jem.20180661

144. Nemeth MJ, Topol L, Anderson SM, Yang Y, Bodine DM. Wnt5a inhibits canonical Wnt signaling in hematopoietic stem cells and enhances repopulation. Proc Natl Acad Sci USA. (2007) 104:15436-41. doi: 10.1073/pnas.0704747104

145. Keller JR, Mantel C, Sing GK, Ellingsworth LR, Ruscetti SK, Ruscetti FW. Transforming growth factor beta 1 selectively regulates early murine hematopoietic progenitors and inhibits the growth of IL-3dependent myeloid leukemia cell lines. J Exp Med. (1988) 168:737-50. doi: 10.1084/jem.168.2.737

146. Yamazaki S, Iwama A, Takayanagi S, Eto K, Ema H, Nakauchi H. TGF-beta as a candidate bone marrow niche signal to induce hematopoietic stem cell hibernation. Blood. (2009) 113:1250-6. doi: 10.1182/blood-2008-04-146480

147. Bragado P, Estrada Y, Parikh F, Krause S, Capobianco C, Farina HG, et al. TGF-beta2 dictates disseminated tumour cell fate in target organs through TGF-beta-RIII and p38alpha/beta signalling. Nat Cell Biol. (2013) 15:135161. doi: $10.1038 / \mathrm{ncb} 2861$

148. Yumoto K, Eber MR, Wang J, Cackowski FC, Decker AM, Lee E, et al. Axl is required for TGF-beta2-induced dormancy of prostate cancer cells in the bone marrow. Sci Rep. (2016) 6:36520. doi: 10.1038/srep36520

149. Veschi V, Mangiapane LR, Nicotra A, Di Franco S, Scavo E, Apuzzo $\mathrm{T}$, et al. Targeting chemoresistant colorectal cancer via systemic administration of a BMP7 variant. Oncogene. (2020) 39:987-1003. doi: 10.1038/s41388-019-1047-4

150. Gao H, Chakraborty G, Lee-Lim AP, Mo Q, Decker M, Vonica A, et al. The BMP inhibitor coco reactivates breast cancer cells at lung metastatic sites. Cell. (2012) 150:764-79. doi: 10.1016/j.cell.2012.06.035

151. Sansone P, Ceccarelli C, Berishaj M, Chang Q, Rajasekhar VK, Perna F, et al. Self-renewal of CD133(hi) cells by IL6/Notch3 signalling regulates endocrine resistance in metastatic breast cancer. Nat Commun. (2016) 7:10442. doi: $10.1038 /$ ncomms 10442

152. Ono M, Kosaka N, Tominaga N, Yoshioka Y, Takeshita F, Takahashi RU, et al. Exosomes from bone marrow mesenchymal stem cells contain a microRNA that promotes dormancy in metastatic breast cancer cells. Sci Signal. (2014) 7:ra63. doi: 10.1126/scisignal.2005231

153. Bliss SA, Sinha G, Sandiford OA, Williams LM, Engelberth DJ, Guiro K, et al. Mesenchymal stem cell-derived exosomes stimulate cycling quiescence and early breast cancer dormancy in bone marrow. Cancer Res. (2016) 76:5832-44. doi: 10.1158/0008-5472.CAN-16-1092

154. Bartosh TJ, Ullah M, Zeitouni S, Beaver J, Prockop DJ. Cancer cells enter dormancy after cannibalizing mesenchymal stem/stromal cells. (MSCs). Proc Natl Acad Sci USA. (2016) 113:E6447-56. doi: 10.1073/pnas.1612290113

155. Matsuo K, Irie N. Osteoclast-osteoblast communication. Arch Biochem Biophys. (2008) 473:201-9. doi: 10.1016/j.abb.2008.03.027

156. Lu X, Mu E, Wei Y, Riethdorf S, Yang Q, Yuan M, et al. VCAM-1 promotes osteolytic expansion of indolent bone micrometastasis of breast cancer by engaging alpha4betalpositive osteoclast progenitors. Cancer Cell. (2011) 20:701-14. doi: 10.1016/j.ccr.2011.11.002

157. Albrengues J, Shields MA, Ng D, Park CG, Ambrico A, Poindexter $\mathrm{ME}$, et al. Neutrophil extracellular traps produced during inflammation awaken dormant cancer cells in mice. Science. (2018) 361:eaao4227. doi: 10.1126/science.aao4227

158. Kienast Y, Von Baumgarten L, Fuhrmann M, Klinkert WE, Goldbrunner R, Herms J, et al. Real-time imaging reveals the single steps of brain metastasis formation. Nat Med. (2010) 16:116-22. doi: 10.1038/nm.2072

159. Cao Z, Ding BS, Guo P, Lee SB, Butler JM, Casey SC, et al. Angiocrine factors deployed by tumor vascular niche induce B cell lymphoma invasiveness and chemoresistance. Cancer Cell. (2014) 25:350-65. doi: 10.1016/j.ccr.2014.02.005

160. Price TT, Burness ML, Sivan A, Warner MJ, Cheng R, Lee CH, et al. Dormant breast cancer micrometastases reside in specific bone marrow niches that regulate their transit to and from bone. Sci Transl Med. (2016) 8:340ra373. doi: 10.1126/scitranslmed.aad4059

161. Butler JM, Kobayashi H, Rafii S. Instructive role of the vascular niche in promoting tumour growth and tissue repair by angiocrine factors. Nat Rev Cancer. (2010) 10:138-46. doi: 10.1038/nrc2791

162. Fessler E, Dijkgraaf FE, De Sousa EMF, Medema JP. Cancer stem cell dynamics in tumor progression and metastasis: is the microenvironment to blame? Cancer Lett. (2013) 341:97-104. doi: 10.1016/j.canlet.2012.10.015

163. Charles N, Holland EC. The perivascular niche microenvironment in brain tumor progression. Cell Cycle. (2010) 9:3012-21. doi: 10.4161/cc.9.15.12710 
164. Haas TL, Sciuto MR, Brunetto L, Valvo C, Signore M, Fiori $\mathrm{ME}$, et al. Integrin alpha7 is a functional marker and potential therapeutic target in glioblastoma. Cell Stem Cell. (2017) 21:35-50.e39. doi: 10.1016/j.stem.2017.04.009

165. Pallini R, Ricci-Vitiani L, Banna GL, Signore M, Lombardi D, Todaro $\mathrm{M}$, et al. Cancer stem cell analysis and clinical outcome in patients with glioblastoma multiforme. Clin Cancer Res. (2008) 14:8205-12. doi: 10.1158/1078-0432.CCR-08-0644

166. Malanchi I, Santamaria-Martinez A, Susanto E, Peng H, Lehr HA, Delaloye JF, et al. Interactions between cancer stem cells and their niche govern metastatic colonization. Nature. (2011) 481:85-9. doi: 10.1038/nature10694

167. Mcallister SS, Gifford AM, Greiner AL, Kelleher SP, Saelzler MP, Ince TA, et al. Systemic endocrine instigation of indolent tumor growth requires osteopontin. Cell. (2008) 133:994-1005. doi: 10.1016/j.cell.2008.04.045

168. Ouyang G, Wang Z, Fang X, Liu J, Yang CJ. Molecular signaling of the epithelial to mesenchymal transition in generating and maintaining cancer stem cells. Cell Mol Life Sci. (2010) 67:2605-18. doi: 10.1007/s00018-010-0338-2

169. Oskarsson T, Acharyya S, Zhang XH, Vanharanta S, Tavazoie SF, Morris PG, et al. Breast cancer cells produce tenascin $\mathrm{C}$ as a metastatic niche component to colonize the lungs. Nat Med. (2011) 17:867-74. doi: 10.1038/nm.2379

170. Frantz C, Stewart KM, Weaver VM. The extracellular matrix at a glance. $J$ Cell Sci. (2010) 123:4195-200. doi: 10.1242/jcs.023820

171. Walker C, Mojares E, Del Rio Hernandez A. Role of extracellular matrix in development and cancer progression. Int J Mol Sci. (2018) 19:3028. doi: 10.3390/ijms19103028

172. Poltavets V, Kochetkova M, Pitson SM, Samuel MS. The role of the extracellular matrix and its molecular and cellular regulators in cancer cell plasticity. Front Oncol. (2018) 8:431. doi: 10.3389/fonc.2018.00431

173. Aguirre Ghiso JA, Kovalski K, Ossowski L. Tumor dormancy induced by downregulation of urokinase receptor in human carcinoma involves integrin and MAPK signaling. J Cell Biol. (1999) 147:89-104. doi: $10.1083 /$ jcb.147.1.89

174. Aguirre-Ghiso JA. How dormant cancer persists and reawakens. Science. (2018) 361:1314-5. doi: 10.1126/science.aav0191

175. Cox TR, Bird D, Baker AM, Barker HE, Ho MW, Lang G, et al. Editor's note: LOX-mediated collagen cross-linking is responsible for fibrosis-enhanced metastasis. Cancer Res. (2019) 79:5124. doi: 10.1158/0008-5472.CAN-19-2419

176. El Touny LH, Vieira A, Mendoza A, Khanna C, Hoenerhoff MJ, Green JE. Combined SFK/MEK inhibition prevents metastatic outgrowth of dormant tumor cells. J Clin Invest. (2014) 124:156-68. doi: 10.1172/JCI70259

177. Simpkins F, Jang K, Yoon H, Hew KE, Kim M, Azzam DJ, et al. Dual Src and MEK inhibition decreases ovarian cancer growth and targets tumor initiating stem-like cells. Clin Cancer Res. (2018) 24:4874-86. doi: 10.1158/1078-0432.CCR-17-3697

178. Gao H, Chakraborty G, Zhang Z, Akalay I, Gadiya M, Gao Y, et al. Multi-organ site metastatic reactivation mediated by non-canonical discoidin domain receptor 1 signaling. Cell. (2016) 166:47-62. doi: 10.1016/j.cell.2016.06.009

179. Barkan D, Kleinman H, Simmons JL, Asmussen H, Kamaraju AK, Hoenorhoff MJ, et al. Inhibition of metastatic outgrowth from single dormant tumor cells by targeting the cytoskeleton. Cancer Res. (2008) 68:6241-50. doi: 10.1158/0008-5472.CAN-07-6849

180. Shibue T, Weinberg RA. Integrin betal-focal adhesion kinase signaling directs the proliferation of metastatic cancer cells disseminated in the lungs. Proc Natl Acad Sci USA. (2009) 106:10290-5. doi: 10.1073/pnas.0904227106

181. Schrader J, Gordon-Walker TT, Aucott RL, Van Deemter M, Quaas A, Walsh S, et al. Matrix stiffness modulates proliferation, chemotherapeutic response, and dormancy in hepatocellular carcinoma cells. Hepatology. (2011) 53:1192-205. doi: 10.1002/hep.24108

182. Reid SE, Kay EJ, Neilson LJ, Henze AT, Serneels J, Mcghee EJ, et al. Tumor matrix stiffness promotes metastatic cancer cell interaction with the endothelium. EMBO J. (2017) 36:2373-89. doi: 10.15252/embj.201694912

183. Liu Y, Lv J, Liang $\mathrm{X}$, Yin $\mathrm{X}$, Zhang $\mathrm{L}$, Chen $\mathrm{D}$, et al. Fibrin stiffness mediates dormancy of tumor-repopulating cells via a Cdc42Driven Tet2 epigenetic program. Cancer Res. (2018) 78:3926-37. doi: 10.1158/0008-5472.CAN-17-3719
184. Barney LE, Hall CL, Schwartz AD, Parks AN, Sparages C, Galarza S, et al. Tumor cell-organized fibronectin maintenance of a dormant breast cancer population. Sci $A d v$. (2020) 6:eaaz4157. doi: 10.1126/sciadv.aaz4157

185. Baeriswyl V, Christofori G. The angiogenic switch in carcinogenesis. Semin Cancer Biol. (2009) 19:329-37. doi: 10.1016/j.semcancer.2009.05.003

186. Hanahan D, Weinberg RA. Hallmarks of cancer: the next generation. Cell. (2011) 144:646-74. doi: 10.1016/j.cell.2011.02.013

187. Papetti M, Herman IM. Mechanisms of normal and tumor-derived angiogenesis. Am J Physiol Cell Physiol. (2002) 282:C947-70. doi: 10.1152/ajpcell.00389.2001

188. Folberg R, Hendrix MJ, Maniotis AJ. Vasculogenic mimicry and tumor angiogenesis. Am J Pathol. (2000) 156:361-81. doi: 10.1016/S0002-9440(10)64739-6

189. Naumov GN, Akslen LA, Folkman J. Role of angiogenesis in human tumor dormancy: animal models of the angiogenic switch. Cell Cycle. (2006) 5:1779-87. doi: 10.4161/cc.5.16.3018

190. Luo W, Wang Y. Hypoxia mediates tumor malignancy and therapy resistance. Adv Exp Med Biol. (2019) 1136:1-18. doi: 10.1007/978-3-030-12734-3_1

191. Bellot G, Garcia-Medina R, Gounon P, Chiche J, Roux D, Pouyssegur J, et al. Hypoxia-induced autophagy is mediated through hypoxia-inducible factor induction of BNIP3 and BNIP3L via their BH3 domains. Mol Cell Biol. (2009) 29:2570-81. doi: 10.1128/MCB.00166-09

192. Bayer C, Vaupel P. Acute versus chronic hypoxia in tumors: controversial data concerning time frames and biological consequences. Strahlenther Onkol. (2012) 188:616-27. doi: 10.1007/s00066-012-0085-4

193. Eales KL, Hollinshead KE, Tennant DA. Hypoxia and metabolic adaptation of cancer cells. Oncogenesis. (2016) 5:e190. doi: 10.1038/oncsis.2015.50

194. Michiels C, Tellier C, Feron O. Cycling hypoxia: a key feature of the tumor microenvironment. Biochim Biophys Acta. (2016) 1866:76-86. doi: 10.1016/j.bbcan.2016.06.004

195. Kang SY, Halvorsen OJ, Gravdal K, Bhattacharya N, Lee JM, Liu NW, et al. Prosaposin inhibits tumor metastasis via paracrine and endocrine stimulation of stromal p53 and Tsp-1. Proc Natl Acad Sci USA. (2009) 106:12115-20. doi: 10.1073/pnas.0903120106

196. Hendrix MJ, Seftor EA, Hess AR, Seftor RE. Vasculogenic mimicry and tumour-cell plasticity: lessons from melanoma. Nat Rev Cancer. (2003) 3:411-21. doi: 10.1038/nrc1092

197. Ricci-Vitiani L, Pallini R, Biffoni M, Todaro M, Invernici G, Cenci T, et al. Tumour vascularization via endothelial differentiation of glioblastoma stem-like cells. Nature. (2010) 468:824-8. doi: 10.1038/nature09557

198. Bao S, Wu Q, Sathornsumetee S, Hao Y, Li Z, Hjelmeland AB, et al. Stem cell-like glioma cells promote tumor angiogenesis through vascular endothelial growth factor. Cancer Res. (2006) 66:7843-8. doi: 10.1158/0008-5472.CAN-06-1010

199. Calabrese C, Poppleton H, Kocak M, Hogg TL, Fuller C, Hamner B, et al. A perivascular niche for brain tumor stem cells. Cancer Cell. (2007) 11:69-82. doi: 10.1016/j.ccr.2006.11.020

200. Beck B, Driessens G, Goossens S, Youssef KK, Kuchnio A, Caauwe A, et al. A vascular niche and a VEGF-Nrp1 loop regulate the initiation and stemness of skin tumours. Nature. (2011) 478:399-403. doi: 10.1038/nature10525

201. David L, Feige JJ, Bailly S. Emerging role of bone morphogenetic proteins in angiogenesis. Cytokine Growth Factor Rev. (2009) 20:203-12. doi: 10.1016/j.cytogfr.2009.05.001

202. Indraccolo S, Minuzzo S, Masiero M, Pusceddu I, Persano L, Moserle $\mathrm{L}$, et al. Cross-talk between tumor and endothelial cells involving the Notch3Dll4 interaction marks escape from tumor dormancy. Cancer Res. (2009) 69:1314-23. doi: 10.1158/0008-5472.CAN08-2791

203. Giuriato S, Ryeom S, Fan AC, Bachireddy P, Lynch RC, Rioth MJ, et al. Sustained regression of tumors upon MYC inactivation requires p53 or thrombospondin-1 to reverse the angiogenic switch. Proc Natl Acad Sci USA. (2006) 103:16266-71. doi: 10.1073/pnas.0608017103

204. Li Z, Bao S, Wu Q, Wang H, Eyler C, Sathornsumetee S, et al. Hypoxiainducible factors regulate tumorigenic capacity of glioma stem cells. Cancer Cell. (2009) 15:501-13. doi: 10.1016/j.ccr.2009.03.018

205. Harris AL. Hypoxia-a key regulatory factor in tumour growth. Nat Rev Cancer. (2002) 2:38-47. doi: 10.1038/nrc704 
206. Almog N, Ma L, Raychowdhury R, Schwager C, Erber R, Short $\mathrm{S}$, et al. Transcriptional switch of dormant tumors to fastgrowing angiogenic phenotype. Cancer Res. (2009) 69:836-44. doi: 10.1158/0008-5472.CAN-08-2590

207. Schreiber RD, Old LJ, Smyth MJ. Cancer immunoediting: integrating immunity's roles in cancer suppression and promotion. Science. (2011) 331:1565-70. doi: 10.1126/science. 1203486

208. Dunn GP, Old LJ, Schreiber RD. The three Es of cancer immunoediting. Annu Rev Immunol. (2004) 22:329-60. doi: 10.1146/annurev.immunol.22.012703.104803

209. Kauffman HM, Mcbride MA, Delmonico FL. First report of the united network for organ sharing transplant tumor registry: donors with a history of cancer. Transplantation. (2000) 70:1747-51. doi: 10.1097/00007890-200012270-00014

210. Mackie RM, Reid R, Junor B. Fatal melanoma transferred in a donated kidney 16 years after melanoma surgery. $N$ Engl J Med. (2003) 348:567-8. doi: 10.1056/NEJM200302063480620

211. Buell JF, Beebe TM, Trofe J, Gross TG, Alloway RR, Hanaway MJ, et al. Donor transmitted malignancies. Ann Transplant. (2004) 9:53-6.

212. Penn I. Malignant melanoma in organ allograft recipients. Transplantation. (1996) 61:274-8. doi: 10.1097/00007890-199601270-00019

213. Suranyi MG, Hogan PG, Falk MC, Axelsen RA, Rigby R, Hawley C, et al. Advanced donor-origin melanoma in a renal transplant recipient: immunotherapy, cure, and retransplantation. Transplantation. (1998) 66:655-61. doi: 10.1097/00007890-199809150-00020

214. Jimsheleishvili S, Alshareef AT, Papadimitriou K, Bregy A, Shah AH, Graham RM, et al. Extracranial glioblastoma in transplant recipients. J Cancer Res Clin Oncol. (2014) 140:801-7. doi: 10.1007/s00432-014-1625-3

215. Cozar JM, Aptsiauri N, Tallada M, Garrido F, Ruiz-Cabello F. Late pulmonary metastases of renal cell carcinoma immediately after posttransplantation immunosuppressive treatment: a case report. J Med Case Rep. (2008) 2:111. doi: 10.1186/1752-1947-2-111

216. Montgomery TR, Whitlock GF, Nohlgren JE, Lewis AM. What becomes of the patient with latent or occult carcinoma of the prostate. J Urol. (1961) 86:655-8. doi: 10.1016/S0022-5347(17)65239-X

217. Harach HR, Franssila KO, Wasenius VM. Occult papillary carcinoma of the thyroid. A "normal" finding in Finland. a systematic autopsy study. Cancer. (1985) 56:531-8.

218. Nielsen M, Thomsen JL, Primdahl S, Dyreborg U, Andersen JA. Breast cancer and atypia among young and middle-aged women: a study of 110 medicolegal autopsies. Br J Cancer. (1987) 56:814-9. doi: 10.1038/bjc.1987.296

219. Loeb LA, Harris CC. Advances in chemical carcinogenesis: a historical review and prospective. Cancer Res. (2008) 68:6863-72. doi: 10.1158/0008-5472.CAN-08-2852

220. Uhr JW, Pantel K. Controversies in clinical cancer dormancy. Proc Natl Acad Sci USA. (2011) 108:12396-400. doi: 10.1073/pnas.1106613108

221. Mahvi DA, Liu R, Grinstaff MW, Colson YL, Raut CP. Local cancer recurrence: the realities, challenges, and opportunities for new therapies. $C A$ Cancer J Clin. (2018) 68:488-505. doi: 10.3322/caac.21498

222. Karrison TG, Ferguson DJ, Meier P. Dormancy of mammary carcinoma after mastectomy. J Natl Cancer Inst. (1999) 91:80-5. doi: 10.1093/jnci/91.1.80

223. Freedland SJ, Moul JW. Prostate specific antigen recurrence after definitive therapy. J Urol. (2007) 177:1985-91. doi: 10.1016/j.juro.2007.01.137

224. Mcnichols DW, Segura JW, Deweerd JH. Renal cell carcinoma: long-term survival and late recurrence. J Urol. (1981) 126:17-23. doi: 10.1016/S0022-5347(17)54359-1

225. Tsao H, Cosimi AB, Sober AJ. Ultra-late recurrence. (15 years or longer) of cutaneous melanoma. Cancer. (1997) 79:2361-70.

226. Davis TA, Maloney DG, Czerwinski DK, Liles TM, Levy R. Anti-idiotype antibodies can induce long-term complete remissions in non-Hodgkin's lymphoma without eradicating the malignant clone. Blood. (1998) 92:118490. doi: 10.1182/blood.V92.4.1184

227. Yilmaz M, Wang F, Loghavi S, Bueso-Ramos C, Gumbs C, Little L, et al. Late relapse in acute myeloid leukemia. (AML): clonal evolution or therapyrelated leukemia? Blood Cancer J. (2019) 9:7. doi: 10.1038/s41408-019-0170-3

228. Farrar JD, Katz KH, Windsor J, Thrush G, Scheuermann RH, Uhr JW, et al. Cancer dormancy. VII. A regulatory role for $\mathrm{CD} 8+\mathrm{T}$ cells and
IFN-gamma in establishing and maintaining the tumor-dormant state. $J$ Immunol. (1999) 162:2842-9.

229. Morecki S, Pugatsch T, Levi S, Moshel Y, Slavin S. Tumor-cell vaccination induces tumor dormancy in a murine model of B-cell leukemia/lymphoma. (BCL1). Int J Cancer. (1996) 65:204-8.

230. Granziero L, Krajewski S, Farness P, Yuan L, Courtney MK, Jackson MR, et al. Adoptive immunotherapy prevents prostate cancer in a transgenic animal model. Eur J Immunol. (1999) 29:1127-38.

231. Mahnke YD, Schwendemann J, Beckhove P, Schirrmacher V. Maintenance of long-term tumour-specific T-cell memory by residual dormant tumour cells. Immunology. (2005) 115:325-36. doi: 10.1111/j.1365-2567.200 5.02163.x

232. Loeser S, Loser K, Bijker MS, Rangachari M, Van Der Burg SH, Wada T, et al. Spontaneous tumor rejection by cbl-b-deficient CD8+ T cells. J Exp Med. (2007) 204:879-91. doi: 10.1084/jem.20061699

233. Eyles J, Puaux AL, Wang X, Toh B, Prakash C, Hong M, et al. Tumor cells disseminate early, but immunosurveillance limits metastatic outgrowth, in a mouse model of melanoma. J Clin Invest. (2010) 120:2030-9. doi: 10.1172/JCI42002

234. Muller-Hermelink N, Braumuller H, Pichler B, Wieder T, Mailhammer R, Schaak $\mathrm{K}$, et al. TNFR1 signaling and IFN-gamma signaling determine whether $\mathrm{T}$ cells induce tumor dormancy or promote multistage carcinogenesis. Cancer Cell. (2008) 13:507-18. doi: 10.1016/j.ccr.200 8.04.001

235. Shankaran V, Ikeda H, Bruce AT, White JM, Swanson PE, Old LJ, et al. IFNgamma and lymphocytes prevent primary tumour development and shape tumour immunogenicity. Nature. (2001) 410:1107-11. doi: $10.1038 / 35074122$

236. Teng MW, Vesely MD, Duret H, Mclaughlin N, Towne JE, Schreiber $\mathrm{RD}$, et al. Opposing roles for IL-23 and IL-12 in maintaining occult cancer in an equilibrium state. Cancer Res. (2012) 72:3987-96. doi: 10.1158/0008-5472.CAN-12-1337

237. Maccalli C, Volonte A, Cimminiello C, Parmiani G. Immunology of cancer stem cells in solid tumours. A review Eur J Cancer. (2014) 50:649-55. doi: 10.1016/j.ejca.2013.11.014

238. Maccalli C, Rasul KI, Elawad M, Ferrone S. The role of cancer stem cells in the modulation of anti-tumor immune responses. Semin Cancer Biol. (2018) 53:189-200. doi: 10.1016/j.semcancer.2018.09.006

239. Quesnel B. Tumor dormancy and immunoescape. APMIS. (2008) 116:68594. doi: 10.1111/j.1600-0463.2008.01163.x

240. Beatty GL, Gladney WL. Immune escape mechanisms as a guide for cancer immunotherapy. Clin Cancer Res. (2015) 21:687-92. doi: 10.1158/1078-0432.CCR-14-1860

241. Bloy N, Garcia P, Laumont CM, Pitt JM, Sistigu A, Stoll G, et al. Immunogenic stress and death of cancer cells: contribution of antigenicity vs adjuvanticity to immunosurveillance. Immunol Rev. (2017) 280:165-74. doi: 10.1111/imr.12582

242. Weinhold KJ, Miller DA, Wheelock EF. The tumor dormant state comparison of L5178Y cells used to establish dormancy with those that emerge after its termination. J Exp Med. (1979) 149:745-57. doi: 10.1084/jem.149.3.745

243. Matsuzawa A, Takeda Y, Narita M, Ozawa H. Survival of leukemic cells in a dormant state following cyclophosphamide-induced cure of strongly immunogenic mouse leukemia. (DL811). Int J Cancer. (1991) 49:303-9. doi: 10.1002/ijc.2910490227

244. Enderling H, Hahnfeldt P, Hlatky L, Almog N. Systems biology of tumor dormancy: linking biology and mathematics on multiple scales to improve cancer therapy. Cancer Res. (2012) 72:2172-5. doi: 10.1158/0008-5472.CAN-11-3269

245. Charoentong P, Finotello F, Angelova M, Mayer C, Efremova $\mathrm{M}$, Rieder D, et al. Pan-cancer immunogenomic analyses reveal genotypeimmunophenotype relationships and predictors of response to checkpoint blockade. Cell Rep. (2017) 18:248-62. doi: 10.1016/j.celrep.2016.12.019

246. Pantel K, Schlimok G, Kutter D, Schaller G, Genz T, Wiebecke B, et al Frequent down-regulation of major histocompatibility class I antigen expression on individual micrometastatic carcinoma cells. Cancer Res. (1991) 51:4712-5. 
247. Pommier A, Anaparthy N, Memos N, Kelley ZL, Gouronnec A, Yan $\mathrm{R}$, et al. Unresolved endoplasmic reticulum stress engenders immuneresistant, latent pancreatic cancer metastases. Science. (2018) 360:eaao4908. doi: 10.1126/science.aao4908

248. Agudo J, Park ES, Rose SA, Alibo E, Sweeney R, Dhainaut M, et al. Quiescent tissue stem cells evade immune surveillance. Immunity. (2018) 48:271-85.e275. doi: 10.1016/j.immuni.2018.02.001

249. Bichsel CA, Wang L, Froment L, Berezowska S, Muller S, Dorn $\mathrm{P}$, et al. Increased PD-L1 expression and IL-6 secretion characterize human lung tumor-derived perivascular-like cells that promote vascular leakage in a perfusable microvasculature model. Sci Rep. (2017) 7:10636. doi: 10.1038/s41598-017-09928-1

250. Dieterich LC, Ikenberg K, Cetintas T, Kapaklikaya K, Hutmacher C, Detmar M. Tumor-associated lymphatic vessels upregulate PDL1 to inhibit T-cell activation. Front Immunol. (2017) 8:66. doi: 10.3389/fimmu.2017.00066

251. Schmittnaegel M, Rigamonti N, Kadioglu E, Cassara A, Wyser Rmili C, Kiialainen A, et al. Dual angiopoietin-2 and VEGFA inhibition elicits antitumor immunity that is enhanced by PD-1 checkpoint blockade. Sci Transl Med. (2017) 9:eaak9670. doi: 10.1126/scitranslmed.aak9670

252. Saudemont A, Hamrouni A, Marchetti P, Liu J, Jouy N, Hetuin D, et al. Dormant tumor cells develop cross-resistance to apoptosis induced by CTLs or imatinib mesylate via methylation of suppressor of cytokine signaling 1 . Cancer Res. (2007) 67:4491-8. doi: 10.1158/0008-5472.CAN-06-1627

253. Zamai L, Ponti C, Mirandola P, Gobbi G, Papa S, Galeotti L, et al. NK cells and cancer. J Immunol. (2007) 178:4011-6. doi: 10.4049/jimmunol.178.7.4011

254. Shimasaki N, Jain A, Campana D. NK cells for cancer immunotherapy. Nat Rev Drug Discov. (2020) 19:200-18. doi: 10.1038/s41573-019-0052-1

255. Malladi S, Macalinao DG, Jin X, He L, Basnet H, Zou Y, et al. Metastatic latency and immune evasion through autocrine inhibition of WNT. Cell. (2016) 165:45-60. doi: 10.1016/j.cell.2016.02.025

256. Ingangi V, Minopoli M, Ragone C, Motti ML, Carriero MV. Role of microenvironment on the fate of disseminating cancer stem cells. Front Oncol. (2019) 9:82. doi: 10.3389/fonc.2019.00082

257. Giles AJ, Reid CM, Evans JD, Murgai M, Vicioso Y, Highfill SL, et al. Activation of hematopoietic stem/progenitor cells promotes immunosuppression within the premetastatic niche. Cancer Res. (2016) 76:1335-47. doi: 10.1158/0008-5472.CAN-15-0204

258. Liu Y, Cao X. Immunosuppressive cells in tumor immune escape and metastasis. J Mol Med. (2016) 94:509-22. doi: 10.1007/s00109-015-1376-x

259. Kryczek I, Zou L, Rodriguez P, Zhu G, Wei S, Mottram P, et al. B7H4 expression identifies a novel suppressive macrophage population in human ovarian carcinoma. J Exp Med. (2006) 203:871-81. doi: $10.1084 /$ jem. 20050930

260. Kuang DM, Zhao Q, Peng C, Xu J, Zhang JP, Wu C, et al. Activated monocytes in peritumoral stroma of hepatocellular carcinoma foster immune privilege and disease progression through PD-L1. J Exp Med. (2009) 206:1327-37. doi: 10.1084/jem.20082173

261. Curiel TJ, Coukos G, Zou L, Alvarez X, Cheng P, Mottram P, et al. Specific recruitment of regulatory $\mathrm{T}$ cells in ovarian carcinoma fosters immune privilege and predicts reduced survival. Nat Med. (2004) 10:942-9. doi: $10.1038 / \mathrm{nm} 1093$

262. Mcallister SS, Weinberg RA. The tumour-induced systemic environment as a critical regulator of cancer progression and metastasis. Nat Cell Biol. (2014) 16:717-27. doi: 10.1038/ncb3015

263. Kenkel JA, Tseng WW, Davidson MG, Tolentino LL, Choi O, Bhattacharya $\mathrm{N}$, et al. An immunosuppressive dendritic cell subset accumulates at secondary sites and promotes metastasis in pancreatic cancer. Cancer Res. (2017) 77:4158-70. doi: 10.1158/0008-5472.CAN-16-2212

264. Priego N, Zhu L, Monteiro C, Mulders M, Wasilewski D, Bindeman W, et al. STAT3 labels a subpopulation of reactive astrocytes required for brain metastasis. Nat Med. (2018) 24:1024-35. doi: 10.1038/s41591-018-0044-4

265. Coffelt SB, Kersten K, Doornebal CW, Weiden J, Vrijland K, Hau CS, et al. IL-17-producing gammadelta $\mathrm{T}$ cells and neutrophils conspire to promote breast cancer metastasis. Nature. (2015) 522:345-8. doi: $10.1038 /$ nature 14282

266. Wculek SK, Malanchi I. Neutrophils support lung colonization of metastasisinitiating breast cancer cells. Nature. (2015) 528:413-7. doi: $10.1038 /$ nature 16140
267. Rabinovich GA, Gabrilovich D, Sotomayor EM. Immunosuppressive strategies that are mediated by tumor cells. Annu Rev Immunol. (2007) 25:267-96. doi: 10.1146/annurev.immunol.25.022106.141609

268. Vinay DS, Ryan EP, Pawelec G, Talib WH, Stagg J, Elkord E, et al. Immune evasion in cancer: mechanistic basis and therapeutic strategies. Semin Cancer Biol. (2015) 35:S185-98. doi: 10.1016/j.semcancer.2015.03.004

269. Riethdorf S, Pantel K. Disseminated tumor cells in bone marrow and circulating tumor cells in blood of breast cancer patients: current state of detection and characterization. Pathobiology. (2008) 75:140-8. doi: 10.1159/000123852

270. Kowalik A, Kowalewska M, Gozdz S. Current approaches for avoiding the limitations of circulating tumor cells detection methods-implications for diagnosis and treatment of patients with solid tumors. Transl Res. (2017) 185:58-84.e15. doi: 10.1016/j.trsl.2017.04.002

271. Zhang L, Ridgway LD, Wetzel MD, Ngo J, Yin W, Kumar D, et al. The identification and characterization of breast cancer CTCs competent for brain metastasis. Sci Transl Med. (2013) 5:180ra148. doi: 10.1126/scitranslmed.3005109

272. Larsen SB, Cowley CJ, Fuchs E. Epithelial cells: liaisons of immunity. Curr Opin Immunol. (2020) 62:45-53. doi: 10.1016/j.coi.2019.11.004

273. Lu X, Kang Y. Cell fusion as a hidden force in tumor progression. Cancer Res. (2009) 69:8536-9. doi: 10.1158/0008-5472.CAN-09-2159

274. Burkardt HJ. Standardization and quality control of PCR analyses. Clin Chem Lab Med. (2000) 38:87-91. doi: 10.1515/CCLM.2000.014

275. Pantel K, Schlimok G, Angstwurm M, Weckermann D, Schmaus W, Gath $\mathrm{H}$, et al. Methodological analysis of immunocytochemical screening for disseminated epithelial tumor cells in bone marrow. J Hematother. (1994) 3:165-73. doi: 10.1089/scd.1.1994.3.165

276. Pantel K, Alix-Panabieres C. Bone marrow as a reservoir for disseminated tumor cells: a special source for liquid biopsy in cancer patients. Bonekey Rep. (2014) 3:584. doi: 10.1038/bonekey.2014.79

277. Aktas B, Tewes M, Fehm T, Hauch S, Kimmig R, Kasimir-Bauer S. Stem cell and epithelial-mesenchymal transition markers are frequently overexpressed in circulating tumor cells of metastatic breast cancer patients. Breast Cancer Res. (2009) 11:R46. doi: 10.1186/bcr2333

278. Raimondi C, Gradilone A, Naso G, Vincenzi B, Petracca A, Nicolazzo C, et al. Epithelial-mesenchymal transition and stemness features in circulating tumor cells from breast cancer patients. Breast Cancer Res Treat. (2011) 130:449-55. doi: 10.1007/s10549-011-1373-x

279. Balic M, Lin H, Young L, Hawes D, Giuliano A, Mcnamara G, et al. Most early disseminated cancer cells detected in bone marrow of breast cancer patients have a putative breast cancer stem cell phenotype. Clin Cancer Res. (2006) 12:5615-21. doi: 10.1158/1078-0432.CCR-06-0169

280. Fluegen G, Avivar-Valderas A, Wang Y, Padgen MR, Williams JK, Nobre $\mathrm{AR}$, et al. Phenotypic heterogeneity of disseminated tumour cells is preset by primary tumour hypoxic microenvironments. Nat Cell Biol. (2017) 19:12032. doi: $10.1038 /$ ncb3465

281. Bartkowiak K, Kwiatkowski M, Buck F, Gorges TM, Nilse L, Assmann $\mathrm{V}$, et al. Disseminated tumor cells persist in the bone marrow of breast cancer patients through sustained activation of the unfolded protein response. Cancer Res. (2015) 75:5367-77. doi: 10.1158/0008-5472.CAN14-3728

282. Hong Y, Fang F, Zhang Q. Circulating tumor cell clusters: What we know and what we expect.. Int J Oncol. (2016) 49:2206-16. doi: 10.3892/ijo.201 6.3747

283. Riethdorf S, O'flaherty L, Hille C, Pantel K. Clinical applications of the cellsearch platform in cancer patients. Adv Drug Deliv Rev. (2018) 125:10221. doi: 10.1016/j.addr.2018.01.011

284. Sai B, Xiang J. Disseminated tumour cells in bone marrow are the source of cancer relapse after therapy. J Cell Mol Med. (2018) 22:5776-86. doi: $10.1111 / \mathrm{jcmm} .13867$

285. Lozar T, Gersak K, Cemazar M, Kuhar CG, Jesenko T. The biology and clinical potential of circulating tumor cells. Radiol Oncol. (2019) 53:131-47. doi: 10.2478/raon-2019-0024

286. Tjensvoll K, Nordgard O, Skjaeveland M, Oltedal S, Janssen E. A. M., Gilje, B. Detection of disseminated tumor cells in bone marrow predict late recurrences in operable breast cancer patients. BMC Cancer. (2019) 19:1131. doi: 10.1186/s12885-019-6268-y 
287. Yang C, Xia BR, Jin WL, Lou G. Circulating tumor cells in precision oncology: clinical applications in liquid biopsy and 3D organoid model. Cancer Cell Int. (2019) 19:341. doi: 10.1186/s12935-019-1067-8

288. Mentis AA, Grivas PD, Dardiotis E, Romas NA, Papavassiliou AG. Circulating tumor cells as Trojan Horse for understanding, preventing, and treating cancer: a critical appraisal. Cell Mol Life Sci. (2020) 77:3671-90. doi: 10.1007/s00018-020-03529-4

289. Karczewski KJ, Snyder MP. Integrative omics for health and disease. Nat Rev Genet. (2018) 19:299-310. doi: 10.1038/nrg.2018.4

290. Sosa MS. Dormancy programs as emerging antimetastasis therapeutic alternatives. Mol Cell Oncol. (2016) 3:e1029062. doi: 10.1080/23723556.2015.1029062

291. Welcker M, Clurman BE. FBW7 ubiquitin ligase: a tumour suppressor at the crossroads of cell division, growth and differentiation. Nat Rev Cancer. (2008) 8:83-93. doi: 10.1038/nrc2290

292. Takeishi S, Matsumoto A, Onoyama I, Naka K, Hirao A, Nakayama KI. Ablation of Fbxw7 eliminates leukemia-initiating cells by preventing quiescence. Cancer Cell. (2013) 23:347-61. doi: 10.1016/j.ccr.2013.01.026

293. Hidayat M, Mitsuishi Y, Takahashi F, Tajima K, Yae T, Miyahara K, et al. Role of FBXW7 in the quiescence of gefitinib-resistant lung cancer stem cells in EGFR-mutant non-small cell lung cancer. Bosn J Basic Med Sci. (2019) 19:355-67. doi: 10.17305/bjbms.2019.4227

294. Essers MA, Offner S, Blanco-Bose WE, Waibler Z, Kalinke U, Duchosal MA, et al. IFNalpha activates dormant haematopoietic stem cells in vivo. Nature. (2009) 458:904-8. doi: 10.1038/nature07815

295. Saito Y, Uchida N, Tanaka S, Suzuki N, Tomizawa-Murasawa M, Sone $\mathrm{A}$, et al. Induction of cell cycle entry eliminates human leukemia stem cells in a mouse model of AML. Nat Biotechnol. (2010) 28:275-80. doi: $10.1038 /$ nbt.1607

296. Wang Q, Bu S, Xin D, Li B, Wang L, Lai D. Autophagy is indispensable for the self-renewal and quiescence of ovarian cancer spheroid cells with stem cell-like properties. Oxid Med Cell Longev. (2018) 2018:7010472. doi: 10.1155/2018/7010472

297. Shen S, Fan J, Cai B, Lv Y, Zeng M, Hao Y, et al. Vascular endothelial growth factor enhances cancer cell adhesion to microvascular endothelium in vivo. Exp Physiol. (2010) 95:369-79. doi: 10.1113/expphysiol.2009.050260

298. Shay G, Lynch CC, Fingleton B. Moving targets: emerging roles for MMPs in cancer progression and metastasis. Matrix Biol. (2015) 44-46:200-6. doi: 10.1016/j.matbio.2015.01.019

299. Nilsson M, Adamo H, Bergh A, Halin Bergstrom S. Inhibition of lysyl oxidase and lysyl oxidase-like enzymes has tumour-promoting and tumoursuppressing roles in experimental prostate cancer. Sci Rep. (2016) 6:19608. doi: $10.1038 /$ srep 19608

300. Qian BZ, Li J, Zhang H, Kitamura T, Zhang J, Campion LR, et al. CCL2 recruits inflammatory monocytes to facilitate breast-tumour metastasis. Nature. (2011) 475:222-5. doi: 10.1038/nature10138

301. Germano G, Frapolli R, Belgiovine C, Anselmo A, Pesce S, Liguori M, et al. Role of macrophage targeting in the antitumor activity of trabectedin. Cancer Cell. (2013) 23:249-62. doi: 10.1016/j.ccr.2013.01.008

302. Wieland E, Rodriguez-Vita J, Liebler SS, Mogler C, Moll I, Herberich SE, et al. Endothelial Notch1 activity facilitates metastasis. Cancer Cell. (2017) 31:355-67. doi: 10.1016/j.ccell.2017.01.007

303. Naume B, Synnestvedt M, Falk RS, Wiedswang G, Weyde K, Risberg $\mathrm{T}$, et al. Clinical outcome with correlation to disseminated tumor cell. (DTC) status after DTC-guided secondary adjuvant treatment with docetaxel in early breast cancer. J Clin Oncol. (2014) 32:3848-57. doi: 10.1200/JCO.2014.56.9327

304. June CH, O'connor RS, Kawalekar OU, Ghassemi S, Milone MC. CAR $\mathrm{T}$ cell immunotherapy for human cancer. Science. (2018) 359:1361-5. doi: 10.1126/science.aar6711

305. Mehta RS, Rezvani K. Chimeric antigen receptor expressing natural killer cells for the immunotherapy of cancer. Front Immunol. (2018) 9:283. doi: $10.3389 /$ fimmu.2018.00283

306. Smith TT, Stephan SB, Moffett HF, Mcknight LE, Ji W, Reiman $\mathrm{D}$, et al. In situ programming of leukaemia-specific $\mathrm{T}$ cells using synthetic DNA nanocarriers. Nat Nanotechnol. (2017) 12:813-20. doi: $10.1038 /$ nnano.2017.57

307. Early Breast Cancer Trialists' Collaborative Group. Effects of chemotherapy and hormonal therapy for early breast cancer on recurrence and 15-year survival: an overview of the randomised trials. Lancet. (2005) 365:1687-717. doi: 10.1016/S0140-6736(05)66544-0

308. Davies C, Pan H, Godwin J, Gray R, Arriagada R, Raina V, et al. Longterm effects of continuing adjuvant tamoxifen to 10 years versus stopping at 5 years after diagnosis of oestrogen receptor-positive breast cancer: ATLAS, a randomised trial. Lancet. (2013) 381:805-16. doi: 10.1016/S0140-6736(12)61963-1

309. Aguirre-Ghiso JA, Liu D, Mignatti A, Kovalski K, Ossowski L. Urokinase receptor and fibronectin regulate the ERK(MAPK) to p38(MAPK) activity ratios that determine carcinoma cell proliferation or dormancy in vivo. Mol Biol Cell. (2001) 12:863-79. doi: 10.1091/mbc.12.4.863

310. Carrio M, Arderiu G, Myers C, Boudreau NJ. Homeobox D10 induces phenotypic reversion of breast tumor cells in a threedimensional culture model. Cancer Res. (2005) 65:7177-85. doi: 10.1158/0008-5472.CAN-04-1717

311. Chen A, Cuevas I, Kenny PA, Miyake H, Mace K, Ghajar C, et al. Endothelial cell migration and vascular endothelial growth factor expression are the result of loss of breast tissue polarity. Cancer Res. (2009) 69:6721-9. doi: 10.1158/0008-5472.CAN-08-4069

312. Catena R, Bhattacharya N, El Rayes T, Wang S, Choi H, Gao D, et al. Bone marrow-derived Gr1+ cells can generate a metastasis-resistant microenvironment via induced secretion of thrombospondin-1. Cancer Discov. (2013) 3:578-89. doi: 10.1158/2159-8290.CD-12-0476

313. Beliveau A, Mott JD, Lo A, Chen EI, Koller AA, Yaswen P, et al. Raf-induced MMP9 disrupts tissue architecture of human breast cells in threedimensional culture and is necessary for tumor growth in vivo. Genes Dev. (2010) 24:2800-11. doi: 10.1101/gad.1990410

314. Adam AP, George A, Schewe D, Bragado P, Iglesias BV, Ranganathan AC, et al. Computational identification of a p38SAPKregulated transcription factor network required for tumor cell quiescence. Cancer Res. (2009) 69:5664-72. doi: 10.1158/0008-5472.CAN-08-3820

315. Adomako A, Calvo V, Biran N, Osman K, Chari A, Paton JC, et al. Identification of markers that functionally define a quiescent multiple myeloma cell sub-population surviving bortezomib treatment. BMC Cancer. (2015) 15:444. doi: 10.1186/s12885-015-1460-1

316. Onder TT, Kara N, Cherry A, Sinha AU, Zhu N, Bernt KM, et al. Chromatin-modifying enzymes as modulators of reprogramming. Nature. (2012) 483:598-602. doi: 10.1038/nature10953

317. Welty CJ, Coleman I, Coleman R, Lakely B, Xia J, Chen S, et al. Single cell transcriptomic analysis of prostate cancer cells. BMC Mol Biol. (2013) 14:6. doi: 10.1186/1471-2199-14-6

318. Chery L, Lam HM, Coleman I, Lakely B, Coleman R, Larson S, et al. Characterization of single disseminated prostate cancer cells reveals tumor cell heterogeneity and identifies dormancy associated pathways. Oncotarget. (2014) 5:9939-51. doi: 10.18632/oncotarget.2480

319. Zeniou M, Feve M, Mameri S, Dong J, Salome C, Chen W, et al. Chemical library screening and structure-function relationship studies identify bisacodyl as a potent and selective cytotoxic agent towards quiescent human glioblastoma tumor stem-like cells. PLoS ONE. (2015) 10:e134793. doi: 10.1371/journal.pone.0134793

320. Zeuner A, Francescangeli F, Contavalli P, Zapparelli G, Apuzzo T, Eramo A, et al. Elimination of quiescent/slow-proliferating cancer stem cells by Bcl-XL inhibition in nonsmall cell lung cancer. Cell Death Differ. (2014) 21:1877-88. doi: $10.1038 / \mathrm{cdd} .2014 .105$

Conflict of Interest: RDM is an advisory board member and research grant recipient from Hibercell, Inc. NY.

The remaining authors declare that the research was conducted in the absence of any commercial or financial relationships that could be construed as a potential conflict of interest.

Copyright (c) 2020 Sistigu, Musella, Galassi, Vitale and De Maria. This is an openaccess article distributed under the terms of the Creative Commons Attribution License (CC BY). The use, distribution or reproduction in other forums is permitted, provided the original author(s) and the copyright owner(s) are credited and that the original publication in this journal is cited, in accordance with accepted academic practice. No use, distribution or reproduction is permitted which does not comply with these terms. 